\title{
Adelbert von Chamisso, Giacomo Leopardi oder die Suche nach dem Unendlichen
}

Dass der große deutsche Dichter der Romantik, eigentlich` ein Franzose war, der während der Französischen Revolution im Alter von elf Jahren mit seiner adeligen Familie aus Frankreich geflohen war, gehört sicherlich zu den schönsten Pointen deutschsprachiger Literatur im 19. Jahrhundert. ${ }^{1}$ Adelbert von Chamisso, ${ }^{2}$ der große Bewunderer Alexander von Humboldts - dem wir uns in dieser Vorlesung bald widmen werden -, nahm sich in späteren Jahren Humboldts Lebensstil durchaus zum Vorbild. Nicht umsonst hatte Chamisso der Erzählung einer von Christen gejagten und gefolterten Guahiba-Indianerin, die er in Humboldts auf Französisch verfasstem amerikanischen Reisebericht - der Relation historique gefunden hatte, ein bemerkenswertes Gedicht gewidmet. ${ }^{3}$ Humboldt fand seinerseits in Chamissos reiseliterarischem Schreiben wohl jene Vorstellung wieder, die er in seiner auf März 1849 datierten „Vorrede zur zweiten und dritten Ausgabe“ seiner Ansichten der Natur als die „Verbindung eines litterarischen und eines rein scientifischen Zweckes“4 ${ }^{4}$ bezeichnet hatte. Es war alles andere als Zufall, dass sich die beiden großen Figuren des deutschen Geisteslebens im 19. Jahrhundert ebenso auf ihren deutsch-französischen Wegen wie dank ihrer Reiseberichte, die sie wechselseitig lasen, freundschaftlich begegneten.

1 Zum biographischen Hintergrund des Dichters und Naturforschers vgl. u. a. die mit einer gewissen Regelhaftigkeit veröffentlichten und das weiter wachsende Interesse an Chamisso dokumentierenden Biographien aus vier Jahrzehnten von Freudel, Werner: Adelbert von Chamisso. Leben und Werk. Leipzig: Philipp Reclam jun. 1980; Fischer, Robert: Adelbert von Chamisso. Weltbürger, Naturforscher und Dichter. Vorwort von Rafik Schami. Mit zahlreichen Abbildungen. Berlin - München: Erika Klopp Verlag 1990; Arz, Maike: Literatur und Lebenskraft. Vitalistische Naturforschung und bürgerliche Literatur um 1800. Stuttgart: M\&P Verlag für Wissenschaft und Forschung 1996; Langner, Beatrix: Der wilde Europäer. Adelbert von Chamisso. Berlin: Matthes \& Seitz 2009.

2 Vgl. das Adelbert von Chamisso gewidmete Teilkapitel in Ette, Ottmar: Mobile Preußen. Ansichten jenseits des Nationalen. Stuttgart: J.B. Metzler Verlag 2019, S. 205-218.

3 Vgl. zu diesem Gedicht Lamping, Dieter: „Ein armer unbedachter Gast“. Adelbert von Chamissos interkulturelle Lyrik. In: Chiellino, Carmine / Shchyhlevska, Natalia (Hg.): Bewegte Sprache. Vom „Gastarbeiterdeutsch“ zum interkulturellen Schreiben. Dresden: Thelen 2014, insb. S. 20-25. 4 Humboldt, Alexander von: Ansichten der Natur mit wissenschaftlichen Erläuterungen. Tübingen: Cotta 1808, S. 9. 


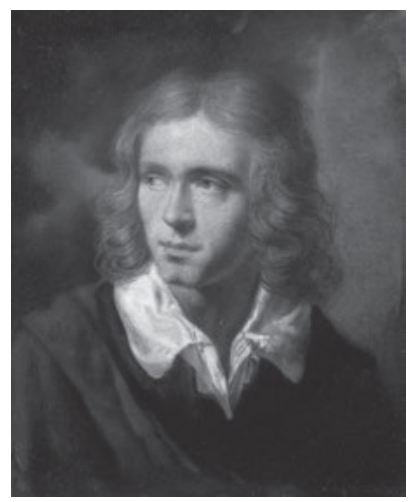

Abb. 47: Aldelbert von Chamisso (Schloss Boncourt bei Ante, Châlons-en-Champagne, 1781 - Berlin, 1838).

Besonders in Chamissos Reise um die Welt war immer wieder einmal von Humboldt zu lesen. So schrieb ersterer in seinem ebenso kunstvoll wie komplex angelegten Bericht von jener zweiten russischen Weltumsegelung, die er von 1815 bis 1818 an Bord der russischen Brigg „Rurik“ unter dem Kommando des Kapitäns Otto von Kotzebue mitgemacht hatte, mit großer Hochachtung für den längst zu Weltruhm gelangten Preußen:

Don Jose de Medinilla y Pineda hatte in Peru, von wo er auf diese Inseln gekommen, Alexander von Humboldt gekannt, und war stolz darauf, ihm ein Mal seinen eigenen Hut geliehen zu haben, als jener einen gesucht, um an dem Hof des Vicekönigs zu erscheinen. Wir haben später zu Manila, welche Hauptstadt der Philippinen von jeher mit der Neuen Welt in lebendigem Verkehr gestanden hat, oft den weltberühmten Namen unseres Landsmanns mit Verehrung nennen hören, und mehrere, besonders geistliche Herrn angetroffen, die ihn gesehen oder gekannt zu haben sich rühmten. ${ }^{5}$

Doch nicht nur der Weltruhm, sondern auch das Wissen und insbesondere die für Humboldts Denk-, Schreib- und Wissenschaftsstil so charakteristische Fähigkeit des Zusammendenkens wurden in Chamissos Reise um die Welt mit der Romanzoffischen Entdeckungs Expedition in den Jahren 1815-18 auf der Brigg Rurik immer wieder hervorgehoben. Gelinge es doch einem Humboldt, der „die Bruchstücke örtlicher meteorologischer Beobachtungen, welche nur noch als dürftige Beiträge zu einer physischen Erdkunde vorhanden sind, zu überschauen, zu beleuchten und unter ein Gesetz zu bringen, isothermische Linien über den Globus zu ziehen versucht, eine Hypothese zur Erklärung der Phänomene der Prüfung der Natur-

5 Chamisso, Adelbert von: Reise um die Welt mit der Romanzoffischen Entdeckungs Expedition in den Jahren 1815-18 auf der Brigg Rurik Kapitän Otto von Kotzebues. In (ders.): Sämtliche Werke. Band II. München: Winkler Verlag 1975, S. 224. 
kundigen zu unterwerfen. “6 Adelbert von Chamisso bewunderte das Wechselspiel von Analyse und Synthese bei seinem längst weltberühmten preußischen Landsmann.

Die Spuren der Verehrung, aber auch der lange Schatten Alexander von Humboldts sind an vielen Stellen von Chamissos Reise um die Welt in expliziter oder impliziter Form leicht zu bemerken. So griff er bei seinen eigenen Untersuchungen etwa auf die Erkenntnisse der von Humboldt entworfenen Pflanzengeographie zurück. ${ }^{7}$ Der Verfasser der von Chamisso zitierten Vues des Cordillères et Monumens des Peuples indigènes de l'Amérique ${ }^{8}$ kommentierte dies in einem Brief an diesen nicht ohne den für Humboldt so typischen Schalk im Nacken, habe Chamisso ihm doch in seinen ,allgemeinen Reisebeobachtungen so manches Pflanzengeographische entzogen“. ${ }^{9}$ Verweise auf die vielfältigen Verbindungen zwischen Humboldt und Chamisso ließen sich leicht mehren, stehen jeweils aber unter einer nicht nur im wissenschaftlichen und epistemologischen Sinne aufschlussreichen Übereinstimmung einer allgemeinen und umfassenden Zielsetzung, sondern auch unter einem Blickwinkel, bei welchem Wissenschaftsprojekt und Lebensprojekt sich bei beiden Forschern wechselseitig beeinflussten. Anders als Chamisso war Alexander von Humboldt gewiss kein ,Romantiker'; er zeigte in seinem Lebens- und Wissenschaftsprojekt vielmehr auf, dass es zwischen der Vernunft der Aufklärung und der Sehnsucht der Romantik nach Synthesen sehr wohl starke Verbindungen gab, welche beide Jahrhunderte keineswegs als klare Gegensätze erscheinen ließen.

Adelbert von Chamissos Reise um die Welt besaß einen gänzlich anderen Zuschnitt als Alexander von Humboldts vielbändiges (und im Übrigen unerschwingliches) amerikanisches Reisewerk. Sie war nicht das Ergebnis einer radikal neuen wissenschaftlichen Epistemologie, wohl aber das Resultat eines umsichtigen literarischen Schaffensprozesses, wie er in anderer, noch zu besprechender Form für Humboldts reiseliterarische Schriften freilich ebenfalls angenommen werden kann. Die Differenz zwischen beiden Reiseberichten liegt bereits in der ganz anderen Natur der Reise begründet, war Chamisso doch - ähnlich wie Georg Forster und sein Vater Reinhold - im Gegensatz zu Humboldt nicht sein

6 Ebda., Bd. II, S. 472f.

7 Vgl. u. a. ebda., Bd. II, S. 308.

8 Vgl. hierzu die deutschsprachige Ausgabe von Humboldt, Alexander von: Ansichten der Kordilleren und Monumente der eingeborenen Völker Amerikas. Aus dem Französischen von Claudia Kalscheuer. Ediert und mit einem Nachwort versehen von Oliver Lubrich und Ottmar Ette. Frankfurt am Main: Eichborn Verlag 2004.

9 Humboldt, Alexander von: Brief an Adelbert von Chamisso [wohl vom 16.5.1836]. Staatsbibliothek zu Berlin, Nachlass Adelbert von Chamisso, acc. ms. 1937, 183. 
eigener Herr, sondern hatte den ihm nicht selten missliebigen Befehlen auf einem russischen Kriegsschiff Folge zu leisten. Die sich daraus ergebenden Unterschiede sind der Reise um die Welt bereits auf den ersten Seiten zu entnehmen.

Adelbert von Chamisso musste sich an Bord der „Rurik“ erst an die ständige Unterordnung unter einen Befehlshabenden gewöhnen. Die Schwierigkeiten, die der recht eigenwillige Chamisso bereits während der Fahrt mit dem jüngeren, aber sehr erfahrenen Kapitän der (nach Admiral Krusensterns Reise) zweiten russischen Weltumsegelung hatte, setzten sich auch nach der Rückkehr nach Europa fort. Es wurde ihm - und dies war kein ungewöhnlicher Vorgang, sondern auch an Bord etwa von britischen Expeditionsschiffen üblich - von höchster Stelle untersagt, seinen Reisebericht vorab unter eigenem Namen zu veröffentlichen, so dass die von ihm erzielten wissenschaftlichen Ergebnisse erst $1821 \mathrm{im}$ dritten Band von Otto von Kotzebues Reisebericht erschienen. ${ }^{10}$

Bereits 1819 hatte Adelbert von Chamisso konzentriert an seinem Bericht über seine eigene „Reise um die Welt“ gearbeitet; aber erst im Jahre 1836, als Chamisso längst einer der großen Vertreter der deutschen Romantik in der Dichtkunst war, konnte das Werk unter seinem eigenen Namen erscheinen. Sein Reisebericht war klar in die beiden Teile „Tagebuch“ sowie „Bemerkungen und Ansichten“ aufgeteilt. Die Rivalität gegenüber dem offiziellen Reisebericht, den die russische Admiralität unter dem Namen Otto von Kotzebues, Sohn von August von Kotzebue, veröffentlichte, war in Chamissos Formulierungen mit Händen zu greifen. Wir müssen diese besonderen Zwänge bei der Abfassung des Reiseberichts unbedingt in unsere Bewertung desselben miteinbeziehen.

Auch wenn die paratextuellen Titelelemente der „Reise um die Welt“ wie auch der „Ansichten“ offenkundige Anspielungen auf Georg Forsters Reise um die Welt, die Ansichten vom Niederrhein sowie Humboldts Ansichten der Natur darstellen mögen, lassen sich weder Aufbau und Struktur noch der von Chamisso angeschlagene Tonfall in die Nähe der so erfolgreichen Vorbilder Georg Forster und Alexander von Humboldt rücken. Der französisch-preußische Dichter ging hier in vielerlei Hinsicht eigene reiseliterarische Wege. Denn ist ein Reisebericht stets auf der literarischen Ebene mit den Gattungsregeln einer Autobiographie verbunden, so wurde Chamissos Reisebericht doch in vielerlei Hinsicht zum Lebensbericht einer Vielzahl von Autobiographismen.

10 Vgl. hierzu Federhofer, Marie-Theres: Lokales Wissen in den Reisebeschreibungen von Otto von Kotzebue und Adelbert von Chamisso. In: Kasten, Erich: Reisen an den Rand des Russischen Reiches: Die wissenschaftliche Erschließung der nordpazifischen Küstengebiete im 18. und 19. Jahrhundert. Fürstenberg/Havel: Kulturstiftung Sibirien 2013, S. 131. 
Im zweiten Teil des Werks boten die „Bemerkungen und Ansichten“ im Kern die bereits im dritten Band von Kotzebues Bericht abgedruckten (und nun teilweise aktualisierten) wissenschaftlichen Resultate der Expedition. Doch entwickelte das „Tagebuch“, der erste Teil von Chamissos Reise um die Welt, die gattungsspezifische Nähe zwischen reiseliterarischen und autobiographischen Schreibformen weiter, so dass die Reise in einem autobiographischen Lektüremodus auch als Lebensreise gelesen werden kann, ja gelesen werden muss. Dabei gestand der Reisende, der erst wenige Jahre vor Beginn seiner großen Fahrt, im Jahre 1812, mit dem Entschluss zum Studium von Medizin und Naturwissenschaften an der neugegründeten Berliner Universität seine Karriere als Naturforscher begonnen hatte, seine Defizite und Schwächen bereitwillig ein. Wo Humboldt nur im privaten Brief an Wilhelm die noch fehlende Kenntnis vieler Pflanzen einräumte, um selbst dort noch wissenschaftliche Fachtermini sofort nachzuliefern, legte Chamisso in seinem veröffentlichten Werk den jeweiligen Stand der eigenen Kenntnisse offen. So wird der subjektive Standpunkt des Reisenden mit einem anfangs wissenschaftlich begrenzten, aber sich zunehmend ausweitenden Horizont freimütig eingeräumt und als autobiographisch reflektierte Entwicklungsund Bildungsgeschichte lesbar. Von einem szientifischen Bericht im Sinne der Aufklärung ist diese Reise um die Welt deutlich entfernt.

Diese Position eines sich romantisch spiegelnden Subjekts machte Chamisso von Beginn seines Berichts an klar. So habe er sich von Anfang an fremd an Bord gefühlt und seine eigenen Beschränkungen deutlich erkannt, wie der erstmals auf hoher See befindliche Reisende, der unter dem Seegang stets zu leiden hatte, schon bei Plymouth mit Blick auf die englische Küste anzeigte:

Die Flut steigt an den Übergangs-Kalk- und Tonschiefer-Klippen bis auf zweiundzwanzig Fuß; und bei der Ebbe enthüllt sich dem Auge des Naturforschers die reichste, wunderbar rätselhafteste Welt. Ich habe seither nirgends einen an Tangen und Seegewürmen gleich reichen Strand angetroffen. Ich erkannte fast keine von diesen Tieren; ich konnte sie in meinen Büchern nicht auffinden, und ich entrüstete mich ob meiner Unwissenheit. Ich habe erst später erfahren, dass wirklich die mehrsten unbekannt und unbeschrieben sein mussten. Ich habe im Verlauf der Reise manches auf diese Weise versäumt, und ich zeichne es hier geflissentlich auf zur Lehre für meine Nachfolger. Beobachtet, ihr Freunde, sammelt, speichert ein für die Wissenschaft, was in euren Bereich kommt, und lasset darin die Meinung euch nicht irren: dieses und jenes müsse ja bekannt sein, und nur ihr wüßtet nicht darum. ${ }^{11}$

11 Chamisso, Adelbert von: Reise um die Welt, Bd. II, S. 24. 
Adelbert von Chamisso war als wissenschaftliches Mitglied der unter russischer Führung stehenden Expedition zweifellos ein Spätberufener. Deutsche Teilnehmer an russischen Weltumsegelungen waren - wie der Kapitän der „Rurik“ weder zuvor noch in späteren Jahrzehnten an Bord russischer Schiffe selten. Es war Chamissos Freund, der Publizist Julius Eduard Hitzig, der entscheidend am Erfolg von dessen Bewerbung um die Teilnahme an der russischen Weltumsegelung beteiligt war. Chamisso selbst war sich der Lücken seiner Ausbildung wohl bewusst: Aber die Unwissenheit war im Sinne des lernenden Subjekts kein Makel, sondern Grundlage eines weiteren Lernprozesses, welchen der Reisebericht selbst darstellt.

Und zu diesem Lernen gehörte die Einsicht, dass selbst die ,eigenen', europäischen Küsten wissenschaftlich noch längst nicht erforscht waren. Das Beobachten, Sammeln und Speichern für die Wissenschaft wird in der angeführten Passage als langwieriges Unterfangen beschrieben, innerhalb dessen sich der Forscher nicht seiner vorübergehenden Unkenntnis zu schämen brauche. Dieser Lernprozess ist für Chamisso Teil eines nicht nur wissenschaftlichen Lebens, das auf dieser Weltreise, auf dieser Lebensreise im Zeichen eines Erlebens steht, welches „die reichste, wunderbar rätselhafteste Welt“12 zum Gegenstand hat. Im „Tagebuch“ wird dieses Welterleben im Spiel zwischen sich erinnerndem und reisendem Ich immer wieder in den Mittelpunkt gerückt. Es führt Chamisso letztlich zu einer weiteren Art von Wissen auf einer Reise, welche freilich romantisch im Zeichen wunderbarer Reichtümer und Rätsel steht. ${ }^{13}$

Wenn Adelbert von Chamisso bereits zum Zeitpunkt seines Studienbeginns im Jahre 1812 als nicht mehr ganz junger Student von einer Weltreise als Naturforscher zu träumen begann, ${ }^{14}$ dann dürften Habitus und Lebensrhythmus eines Alexander von Humboldt an diesem Vorhaben nicht ganz unbeteiligt gewesen sein. Und wenn er in seinem 1813 an seinem Rückzugsort Kunersdorf, ${ }^{15}$ dem „Musenhof“ derer von Itzenplitz entstandenen Welterfolg Peter Schlemihls wundersame Geschichte seinen Helden und Naturforscher mit „Siebenmeilenstiefel[n]

12 Ebda.

13 Vgl. zu diesem Topos u. a. Greenblatt, Stephen: Wunderbare Besitztümer. Die Erfindung des Fremden: Reisende und Entdecker. aus dem Amerikanischen von Robin Cackett. Berlin: Wagenbach 1994.

14 Vgl. Federhofer, Marie-Theres: Lokales Wissen in den Reisebeschreibungen von Otto von Kotzebue und Adelbert von Chamisso, S. 120.

15 Vgl. hierzu ausführlich Sproll, Monika: Adelbert von Chamisso in Cunersdorf. Frankfurt (Oder): Kleist-Museum 2014. 
an den Füßen“16 ausrüstete, so haben die gewaltigen Schritte seines Schlemihl etwas mit jener „Art philosophischer Wut“17 $\mathrm{zu}$ tun, von der Johann Gottfried Herder 1774 mit Blick auf die philosophischen Reisenden seiner Zeit sprach. Sie stehen aber auch ihm Zusammenhang mit jenen „schnellen Schritten, wo der ganze Erdboden dem Europäischen Forschergeiste offenbar werden und jede Lücke in unseren Erfahrungswissenschaften“ schließen werde, ${ }^{18}$ wie dies Georg Forster 1791 treffend für seine Epoche formulierte. Am Ausgang der zweiten Phase beschleunigter Globalisierung waren die Zeichen noch immer auf Weltreisen gestellt, auch wenn der Nationalismus in vielen Ländern - wie stets nach einer Beschleunigungsphase - immer größere Kreise zog. Ich darf an dieser Stelle hinzufügen, dass uns dies zu verstehen heute leicht fällt, leben wir doch nach dem Ende der vierten Phase beschleunigter Globalisierung in einer derartigen Übergangszeit.

Mit ungeheurer Intensität signalisiert Chamisso in seinem Reisebericht aus dem Jahre 1836 jenes neue Welterleben, das ihm als Naturforscher zuteilwerden sollte - ganz so wie sein Peter Schlemihl sich erst langsam der Wirkung seiner Siebenmeilenstiefel bewusst $\mathrm{zu}$ werden beginnt:

\begin{abstract}
Ich wußte nicht, wie mir geschehen war, der erstarrende Frost zwang mich, meine Schritte $\mathrm{zu}$ beschleunigen, ich vernahm nur das Gebrause ferner Gewässer, ein Schritt, und ich war am Eisufer eines Ozeans. Unzählbare Herden von Seehunden stürzten sich vor mir rauschend in die Fluten. Ich folgte diesem Ufer, ich sah wieder nackte Felsen, Land, Birkenund Tannenwälder, ich lief noch ein paar Minuten gerade vor mir hin. Es war erstickend heiß, ich sah mich um, ich stand zwischen schön gebauten Reisfeldern unter Maulbeerbäumen. ${ }^{19}$
\end{abstract}

Es ist gewiss kein Zufall, dass am Ausgang des 19. Jahrhunderts der kubanische Dichter und Essayist José Martí in seinem Epoche machenden und Epoche verkörpernden Essay Nuestra América ${ }^{20}$ im Jahre 1891, mitten in der dritten Phase beschleunigter Globalisierung, die Siebenmeilenstiefel Chamissos erwähnte und gleichsam wieder auspackte. Mit sicherem Gespür für die Entwicklungen seiner

16 Chamisso, Adelbert von: Peter Schlemihls wundersame Reise. In (ders.): Sämtliche Werke, Bd. 1, S. 60.

17 Herder, Johann Gottfried: Auch eine Philosophie der Geschichte zur Bildung der Menschheit, S. 89.

18 Forster, Georg: Die Nordwestküste von Amerika, und der dortige Pelzhandel, S. 390.

19 Chamisso, Adelbert von: Peter Schlemihls wundersame Geschichte, S. 60.

20 Vgl. hierzu Ette, Ottmar: José Martís Nuestra América oder Wege zu einem amerikanischen Humanismus. In: Röseberg, Dorothee (Hg.): El arte de crear memoria. Festschrift zum 80. Geburtstag von Hans-Otto Dill. Berlin: trafo Wissenschaftsverlag 2015, S. 75-98. 
Zeit bezog Martí diese Siebenmeilenstiefel auf die expandierenden Vereinigten Staaten von Amerika und damit auf jenen Riesen, der dem südlichen Amerika bald schon seine Stiefel auf die Brust setzen werde. Wir werden gegen Ende dieser Vorlesung noch sehen, wie richtig José Martí mit seinen Überlegungen lag, diese als Antwort auf die zweite Phase beschleunigter Globalisierung entstandenen Riesenstiefel auf die zu seiner Zeit virulente dritte Phase beschleunigter Globalisierung anzuwenden. Mit den USA wies er auf jene politische, militärische und wirtschaftliche Macht hin, deren Aufstieg zum damaligen Zeitpunkt bereits die hegemoniale Vorherrschaft während der vierten Phase beschleunigter Globalisierung anzeigte. ${ }^{21}$

Die in der soeben zitierten Passage sichtbare Geschwindigkeit, mit welcher der planetarische Raum durchquert wird, entstammte jenem Erleben einer weltweiten Beschleunigung, welche die Erde in der zweiten Phase beschleunigter Globalisierung im 18. Jahrhundert erfasst und verändert hatte. Die Welt hatte sich irreversibel gewandelt, weil die Er-Fahrung dieser Welt sich im Zeichen einer beschleunigten Bewegung weltweit grundlegend verändert hatte. Adelbert von Chamisso und sein literarisches Schreiben verzeichneten diese Veränderungen mit seismographischer Genauigkeit und deuten so die enormen Fähigkeiten der Literaturen der Welt an, Globalisierungsphänomene in all ihren Details zu erfassen. Dabei vermerkt der Seismograph der Literatur nicht jene Faktenoberfläche einer Wirklichkeit, wie sie in der zeitgenössischen Historiographie aufgezeichnet wird, sondern bietet seinem Lesepublikum eine gelebte, lebbare und (nach-)erlebbare Wirklichkeit an, welche gleichsam ins innere Leben der Dinge und Erscheinungen führt.

Die Serie russischer Weltumsegelungen folgte noch dem Modell jener Entdeckungsreisen eines James Cook, eines Jean-François de Lapérouse oder eines Louis Antoine de Bougainville, mit deren Hilfe die Führungsmächte der zweiten Globalisierungsphase Anspruch auf eine globale Führungsrolle wie auf weite zu kolonisierende Landgebiete erhoben hatten. Doch lässt sie sich trotz ihrer Verspätung von mehreren Jahrzehnten doch noch immer jener hier phasenverschobenen Beschleunigung zurechnen, zu deren Protagonisten sich nun auch der in Frankreich geborene Immigrant aus Preußen zählen durfte, der auf einem russischen Kriegsschiff unter deutsch-baltischer Führung die Welt nicht zuletzt zum Nutzen der Russisch-Amerikanischen Handelskompagnie umschiffte.

Russland hatte sich auf den langen Weg zur Weltmacht begeben; und der müde gewordene und seinem Tod schon nahe Chamisso veröffentlichte seine

21 An dieser Stelle nochmals der Hinweis auf die Theorie der verschiedenen Phasen beschleunigter Globalisierung in Ette, Ottmar: TransArea. Eine literarische Globalisierungsgeschichte. Berlin - Boston: Walter de Gruyter 2012. 
Reise um die Welt als einen Bericht, der diesen Weg reflektierte, aber zugleich eine Schlemihl'sche Reise um den Planeten wie um sein eigenes Leben war. Insbesondere in seinem „Tagebuch“ entwickelte er dafür eine besondere, poetisch verdichtete Sprache, die ihren ganz eigenen Zauber entfaltet. Es ist der romantische Zauber des Wunderbaren, des sich der puren Rationalität Entziehenden, der Schlemihls wundersame Reise, aber auch phasenweise den Chamisso'schen Reisebericht umgibt.

Georg Forster und Alexander von Humboldt bedienten sich der beiden großen, rasch weltweit verbreiteten Sprachen der zweiten Phase beschleunigter Globalisierung. Der eine ließ seine Voyage round the world zunächst in englischer und nur wenig später in deutscher Sprache erscheinen, während der andere den größten Teil seines Voyage aux Régions équinoxiales du Nouveau Continent in französischer Sprache vorlegte und nur bestimmte Teile auf Deutsch publizierte. Dagegen wählte der in Frankreich geborene und im Alter von elf Jahren zusammen mit seiner adeligen, gegen die Französische Revolution aufbegehrenden Familie nach Berlin geflüchtete Chamisso für seinen Reisebericht die deutsche Sprache, ohne darüber freilich zu vergessen, effektvoll auf die vielsprachige Welt an Bord der russischen Brigg aufmerksam zu machen. Noch immer ist das Erbe der europäischen, kosmopolitischen „République des Lettres“ der Aufklärung gegenwärtig.

Nicht ohne ein humorvolles Augenzwinkern beschrieb Chamisso immer wieder seine eigene, höchst originelle sprachlich-kulturelle Position innerhalb des Mikrokosmos der „Rurik“, der Welt an Bord des Schiffes. Diese Welt war eine Heterotopie, ein abgeschlossener Ander-Ort, auf dem eine starke Vielsprachigkeit vorherrschte und sich ein Zusammenleben der verschiedenen Sprachen und Dialekte entfaltete. Ebenso verschmitzt wie hintergründig wird dieser sprachliche Mikrokosmos in der Reise um die Welt dann mit dem Makrokosmos außerhalb des Schiffes in Kontakt gebracht.

Eine vielsprachige, nicht auf eine einzige Sprache, auf eine einzige Logik reduzierbare Welt entsteht unter der Feder dieses weitgereisten französischen Preußen. So vermerkte er beispielsweise am Ende seines Aufenthalts auf den Kanaren in seinem Reisebericht:

Zuerst auf Teneriffa, wie später überall im ganzen Umkreis der Erde, haben sich die Wißbegierigen, mit denen ich als ein Wißbegieriger in nähere Berührung kam, Mühe gegeben, den russischen Nationalcharakter an mir, dem Russen, der aber doch nur ein Deutscher, und als Deutscher eigentlich gar ein geborener Franzos, ein Champenois, war, zu studieren. ${ }^{22}$

22 Chamisso, Adelbert von: Reise um die Welt, Bd. II, S. 42. 
Wie russische Puppen stapeln sich die kulturellen Identitätsentwürfe Adelbert von Chamissos ineinander und aufeinander. Und wie ein roter Faden durchzieht das Oszillieren zwischen Zugehörigkeit und Nicht-Zugehörigkeit zu einer Nation Chamissos Bericht von einer Weltumsegelung, die sich just zu Beginn des 19. Jahrhunderts und damit des Jahrhunderts der großen Nationalismen ansiedelt.

Adelbert von Chamisso hatte schon auf den ersten Seiten seines mit Biographemen gespickten Reiseberichts darauf hingewiesen, dass er im Jahre 1813 als gebürtiger Franzose und ehemaliger preußischer Offizier keinen „tätigen Anteil nehmen durfte“23 an der großen nationalen Erhebung gegen die Hegemonie Napoleons über Europa: „Ich hatte ja kein Vaterland mehr, oder noch kein Vaterland“, ${ }^{24}$ all diese Ereignisse ,zerrissen mich wiederholt vielfältig“. ${ }^{25}$ Es ist ein Oszillieren zwischen einem Frankreich, das sich als die „Grande Nation“ versteht, und einem Deutschland, das sich mühevoll aus der Kleinstaaterei zu lösen begann, aber für den vorläufigen Abschluss dieses Prozesses noch lange Jahrzehnte brauchen sollte. All diese Bewegungen eines ständigen Hin und Her sind zumindest vor seiner Reise um die Welt für Adelbert von Chamisso höchst schmerzlich: Er fühlte sich eingepfercht zwischen einem Nicht-Mehr und einem Noch-Nicht.

Adelbert von Chamisso betonte, er habe sich ins preußische Kunersdorf und in die Niederschrift seines Peter Schlemihl geflüchtet, um sich selbst „zu zerstreuen und die Kinder eines Freundes zu ergötzen“. ${ }^{26}$ Waren die Siebenmeilenstiefel nicht die bestmögliche literarische Umsetzung einer identitären Konstruktion aus der ständigen Bewegung, einer Vektopie also, die sich kurze Zeit später mit seiner Reise um die Welt lebbar verwirklichen sollte? Ohne es zu erahnen, entwarf Chamisso mit literarischen Mitteln eine wundersame und wunderbare Welt, in welcher er über die Bewegungen des Reisenden seinen eigenen, neuen Bewegungsort umschreiben und definieren konnte. Er schuf ihn sich wohl zu seiner eigenen Ergötzung, wo er mit Hilfe seiner Siebenmeilenstiefel stets jenseits aller nationalen Grenzen und Zuordnungen war: keine Utopie und auch keine Dystopie, noch nicht einmal eine Heterotopie, sondern eine aus der Bewegung sich speisende Vektopie.

Die Mikrokosmen von Kunersdorf und der „Rurik“ dienten dazu, sich mit sich selbst auf ein weiteres, erweitertes Begreifen seiner Zeit jenseits eines überall aufkeimenden Nationalismus zu verständigen. Bildete er als Migrant nicht das leben-

23 Ebda., Bd. II, S. 11.

24 Ebda.

25 Ebda.

26 Ebda. 
dige Beispiel für ein Leben, das wie im Falle Alexander von Humboldts nicht auf eine Nation, nicht auf eine Nationalität, nicht auf ein bestimmtes Nationalgefühl beschränkt werden konnte und durfte? War er nicht selbst - und darin Humboldt durchaus ähnlich - das beste Beispiel für ein Preußen, das in den Salons der Rahel Levin Varnhagen bereits an der Wende zum 19. Jahrhundert angelegt war und erst mit der napoleonischen Ära die Geschichte seines Aufstiegs im nationalistischen Taumel zu verdrängen begann? Und war das weltoffene Preußen, für das Adelbert von Chamisso wie ein Heinrich von Kleist stand, nicht eines, in welchem sich die Ansichten jenseits des Nationalen faszinierend reflektierten?

Auf dem Weg von Berlin ins dänische Kopenhagen, wo er sich der Expedition unter Otto von Kotzebue anschließen und als offizieller Teilnehmer der russischen Weltumrundung Teil des international bestückten Forschungsteams werden sollte, fand Adelbert von Chamisso nicht ohne ein gewisses Erstaunen an sich „überhaupt die Gabe“, sich „überall gleich zu Hause zu finden““ ${ }^{27}$ Dies war für ihn ein völlig neues Gefühl: überall zuhause zu sein.

So begann er noch vor Beginn seiner ersten und einzigen Weltreise, sich jenseits des Nationalen einzurichten und damit weniger ein Fremdling, der sich überall fremd fühlt, als vielmehr ein Nomade zu sein, dem überall die Bewegung einen Wohnort und ein Leben ohne festen Wohnsitz ein bewegliches ,Zuhause“ bietet. Keines seiner beiden Vaterländer vermisst er fortan; und von seinem internationalen Freundeskreis in Kopenhagen weiß er mitzuteilen, dass er dort „vielleicht die heitersten und fröhlichsten Tage [s]eines Lebens verlebt“ habe. ${ }^{28}$ Adelbert von Chamisso steht für ein Preußen und Europa ein, das seine vielfältigen Herkünfte fröhlich einzubringen und in nicht weniger vielfältige Zukünfte zu übersetzen versteht. Als Nomade wird er - schon auf Friedrich Nietzsches Diktum vorausweisend - zum Europäer.

Mit Georg Forster wie mit Alexander von Humboldt teilt Adelbert von Chamisso auf reiseliterarischem Gebiet die Erfahrung eines translingualen Schreibens, folglich einer „écriture“, die sich auch jenseits der eigenen Muttersprache bewegt und immer wieder zwischen verschiedenen Sprachen pendelt. Gerade dieses Leben und Schreiben ohne feste sprachliche und nationale Koordinaten mag es gewesen sein, was ihm erlaubte, beim Beobachten, Sammeln und Speichern von Daten zu Kulturen anderer Völker stets die Reflexion des eigenen, europäischen Standpunkts miteinzubeziehen. Vermittels dieser kritischen Selbstüberprüfung entwickelte er eine weitaus weniger von Vorurteilen geprägte Sichtweise indigener Kulturen, als dies etwa in Otto von Kotzebues offiziellem Bericht von

27 Ebda., Bd. II, S. 16.

28 Ebda., Bd. II, S. 17. 
der zweiten russischen Weltumsegelung der Fall war. ${ }^{29}$ Chamisso erwies sich als offener Geist, der die Grundüberzeugungen der Romantik und deren Schreibweisen mit einer Nichtbeachtung des überall aufkeimenden Nationalismus kombinierte und außereuropäischen Kulturen sehr offen gegenüberstand.

Noch wenige Jahre zuvor, damals zeitweise im Umkreis von Germaine de Staël und deren Zirkel lebend, war Adelbert von Chamisso der Verzweiflung nahe gewesen. In französischer Sprache drückte er seine Angst aus, nirgendwo seine ,wirkliche‘ Heimat finden zu können: ${ }^{30}$

Mein Vaterland. Ich bin Franzose in Deutschland und Deutscher in Frankreich, Katholik bei den Protestanten und Protestant bei den Katholiken, Philosoph bei den Religionsanhängern und religiöser Cagot bei vorurteilsfreien Leuten; bin ein Weltmann bei den Stubenhockern und ein Pedant bei den Weltläufigen, ein Jakobiner bei den Aristokraten und bei den Demokraten ein Adeliger, ein Mann des Ancien Régime usw. Ich bin nirgendwo am Platze, bin überall ein Fremder - zu viel wollte ich in meine Arme schließen, und alles entgleitet mir. Ich bin unglücklich - - - Da der Platz heute Abend noch nicht vergeben ist, so erlauben sie mir, mich kopfüber in den Fluss zu stürzen ... ${ }^{31}$

Dies ist sicherlich eine der ergreifendsten Darstellungen des Gefühls, ständig zwischen den Stühlen zu sitzen und überall ein Fremdling, nirgendwo zu Hause zu sein. Es schien, als ob es für Adelbert von Chamisso, der an einem 30. Januar des Jahres 1781 unter dem Namen Louis Charles Adélaïde de Chamissot de Boncourt auf Schloss Boncourt unweit von Châlons-en-Champagne geboren wurde, keinen Ort auf dieser Welt geben würde, an dem er sich wohlfühlen könnte. Aber wenn es im Raum schon keinen Ort gab, war dann nicht in der Bewegung eine Heimat $\mathrm{zu}$ finden, war nicht die Vektopie sein eigentlicher Ort?

Der Bericht von seiner Weltreise zeigt uns einen Chamisso, der auf die eigene Zerrissenheit sehr wohl zurückblickt, sie auch nicht ausblendet oder verdrängt, aber gleichsam in eine dynamische Bewegung überführt hat. Es wäre kaum übertrieben zu sagen, dass seine Weltreise mit einem Schlage viele seiner Probleme löste. Weder eine Heterotopie noch eine Atopie und schon gar nicht eine Utopie oder Dystopie haben ihn von seinem spezifischen Fremd-Sein befreit: Es war vielmehr eine Vektopie! Sie erlaubte es dem überall Fremden, zu einem gewiss

29 Vgl. hierzu Federhofer, Marie-Theres: Lokales Wissen in den Reisebeschreibungen von Otto von Kotzebue und Adelbert von Chamisso, s. 133.

30 Vgl. hierzu Fischer, Robert: Adelbert von Chamisso. Weltbürger, Naturforscher und Dichter. Vorwort von Rafik Schami. Mit zahlreichen Abbildungen. Berlin - München: Erika Klopp Verlag 1990, S. 98.

31 Chamisso, Adelbert von: Leben und Briefe. Herausgegeben von Julius Eduard Hitzig. Leipzig: Weidmann'sche Buchhandlung 1942, S. 271. 
nur zeitweiligen Nomaden zu werden, der die jeweils geltenden Lebensformen und Lebensnormen $\mathrm{zu}$ relativieren verstand und versuchte, sich sein eigenes mobiles, an unterschiedlichsten Sprachen und Logiken partizipierendes Zuhause zu schaffen.

Auffällig ist, wieviel von alledem bereits in Chamissos Peter Schlemihls wundersamer Geschichte enthalten ist, so dass man behaupten könnte, er hätte in der literarischen Welt eine Lösung seiner Probleme entworfen, welche er danach gewiss mit etwas Glück bei der späten Aufnahme als Naturforscher an Bord der „Rurik“ - in die Realität umzusetzen verstand. Dabei kam ihm seine Position zwischen verschiedenen Sprachen nunmehr zu Hilfe. So war es gewiss kein Zufall, dass sich Chamisso in seinen letzten wissenschaftlichen Veröffentlichungen bis zu seinem Lebensende mit Struktur und Aufbau der Hawaiianischen Sprache beschäftigte. Denn auch für ihn war die Welt nicht allein aus der Perspektive einer einzigen Sprache zu erfassen und zu begreifen: Seine Welt war die Kommunikation zwischen allen Menschen, und der Besitz der verschiedensten Sprachen war hierfür entscheidend.

Mit einem Schlage lösen sich die starren, unüberwindlichen Grenzmarkierungen auf. Aus den festen Grenzen sind eher mobile Übergänge, aus den wechselseitigen Ausschlussmechanismen eher Übersetzungsprozesse geworden, die dem Fremdling ein nomadisches, viellogisches Wissen erlauben. Dieser Wandlungs- und Verwandlungsprozess ist nicht nur in den stark autobiographisch eingefärbten Passagen von Chamissos Reise um die Welt, sondern auch in der (wissenschaftlichen) Art der multiperspektivischen Auseinandersetzung mit den von ihm untersuchten Gegenständen erkennbar. Mit anderen Worten: Der literarische Reisebericht präsentiert uns eine sehr tiefreichende Veränderung eines Welterlebens, das zunehmend polylogisch geworden ist, mithin verschiedensten Logiken zugleich folgt.

Chamisso schickte als großer Schriftsteller nicht nur eine Mise en abyme des Erzählens von einer Weltreise seiner eigenen Erzählung voraus. ${ }^{32}$ Vielmehr stellte er ihr auch die Formel eines Lebenswissens als Wissen vom Leben im Leben und für das Leben voran: müsse es ihm doch auf der Brigg „Rurik“ „,so wie überhaupt in der Welt ergehen, wo nur das Leben das Leben lehrt“".33 Auf diese Weise bezog er jene „kleine[n] Welt“, ${ }^{34}$ in welche ihn die „Nußschale““35 seines Schiffes

32 Vgl. Chamisso, Adelbert von: Reise um die Welt, Bd. II, S. 15.

33 Ebda., S. 20.

34 Ebda.

35 Ebda. 
nunmehr „eingepreßt“"36 habe, auf jene umfassende Welt, die zu ersterer in einem Verhältnis von Mikrokosmos und Makrokosmos steht. So seltsam es auch klingen mag: Trotz aller Auseinandersetzungen, die er an Bord insbesondere mit seinem Kapitän auszustehen hatte, boten ihm das kleine Schiff und die Vielzahl an Landgängen auf unterschiedlichen Inseln und Kontinenten Gelegenheit genug, seinen ,eigenen' Platz in der Welt zu finden.

Mit diesem Verhältnis zwischen Mikro- und Makrostruktur, auf das wir bereits zuvor gestoßen waren, wird die bewegliche Grundlage seiner sich beständig verändernden Perspektivik auf die Welt hervorgehoben; eine Bewegung, die den sich verändernden Konturen und Kontexten seines Lebens entspricht. Immer wieder zeichneten sich neue Inseln, immer wieder neue Kontinente ab, Möglichkeiten, an Land $\mathrm{zu}$ gehen oder innerlich weiter zu segeln. Dies erlaubt es dem Lesepublikum zu verstehen, dass der Blick auf die ,weite‘ Welt ein sehr spezifischer und vom Kontext des Schiffes selbst her bestimmter ist, ohne dass diese bewegliche Perspektive zu einer ,natürlichen' und nicht mehr hinterfragbaren würde. Die Offenheit des Chamisso'schen Blickes ist nicht nur im Südpazifik, sondern auch an vielen anderen Stationen seiner Weltumsegelung sehr beeindruckend.

Freilich: Auf einem kleinen Schiff - und mehr noch auf einem russischen Kriegsschiff - kann man anderen ,Mitbewohnern' nicht einfach ausweichen; ${ }^{37}$ die hieraus sich ergebenden Problematiken sind solche der Konvivenz, eines notwendigen Zusammenlebens auf begrenztem zur Verfügung stehenden Raum. Dieses Zusammenleben fiel Chamisso keineswegs leicht. Insofern überrascht es nicht, dass sich der romantische deutsche Dichter von adeliger französischer Herkunft immer wieder mit Fragen und Herausforderungen beschäftigt, welche die Konvivenz zwischen verschiedenen Nationen, Sprachen oder Kulturen, zwischen Militärs und Wissenschaftlern, aber auch zwischen Europäern und indigenen Völkern betrifft. Denn diese Konvivenz-Fragen berührten seinen eigenen Ort auf der Welt.

So wie es im Mikrokosmos des Schiffes ständige Konflikte gibt, die einer stark hierarchisierten Verfahrensweise ausgesetzt sind, so werden auch die Formen wie die Normen der Konvivenz von Chamisso ständig im Lichte von Konflikten, ja von Katastrophen untersucht, wie sie auf der Ebene von Machtbeziehungen etwa zwischen Kolonialherren und Kolonisierten auftreten: Adelbert von Chamissos Reise um die Welt stellt die Frage nach dem Zusammenleben auf einer Nussschale, die nichts anderes als die Welt ist. Die Vorstellung vom „Raumschiff

36 Ebda.

37 Ebda., Bd. II, S. 37. 
Erde“"38 ist weit älter als die bemannte Raumfahrt mit ihren Bildern vom Lonely Planet. Sie kann an jedem begrenzten Ort dieses Planeten gemacht werden.

Adelbert von Chamisso sucht bewusst, sich wo irgend möglich von jeder Arroganz der sogenannten ,Zivilisierten“ gegenüber den sogenannten ,Wilden“39 zu distanzieren und eine weitere Perspektive einzunehmen, die dem Maßstab von Alterität und Alterisierung entgeht. So heißt es bei ihm entschieden und mit einem hohen Bewusstsein für die von ihm verwendete Sprache:

Ich ergreife diese Gelegenheit auch hier, gegen die Benennung „Wilde“ in ihrer Anwendung auf die Südsee-Insulaner feierlichen Protest einzulegen. Ich verbinde gern, so wie ich kann, bestimmte Begriffe mit den Wörtern, die ich gebrauche. Ein Wilder ist für mich der Mensch, der ohne festen Wohnsitz, Feldbau und gezähmte Tiere, keinen anderen Besitz kennt, als seine Waffen, mit denen er sich von der Jagd ernährt. Wo den Südsee-Insulanern Verderbtheit der Sitten Schuld gegeben werden kann, scheint mir solche nicht von der Wildheit, sondern vielmehr von der Übergesittung zu zeugen. Die verschiedenen Erfindungen, die Münze, die Schrift u.s.w., welche die verschiedenen Stufen der Gesittung abzumessen geeignet sind, auf denen Völker unseres Kontinentes sich befinden, hören unter so veränderten Bedingungen auf, einen Maßstab abzugeben für diese insularisch abgesonderten Menschenfamilien, die unter diesem wonnigen Himmel ohne Gestern und Morgen dem Momente leben und dem Genusse. ${ }^{40}$

Die sprachkritischen Überlegungen gehen in zivilisationskritische über, welche bei aller romantisierenden Einfärbung - die erste Person Plural deutet es an die eigene europäische Perspektive nicht verleugnen, aber auch nicht länger als allein gültigen „Maßstab“ akzeptieren wollen. Wir dürfen mit Chamisso sagen: Das Problem ist nicht die europäische Perspektive, sondern deren Absolut-Setzung.

Wir können in der oben angeführten Passage den Versuch erkennen, mit den Wörtern zugleich die Tropen der Diskurse wie die Diskurse der Tropen ${ }^{41}$ einer Selbstkritik zu unterziehen, die auf ein viellogisches Verstehen zielt, in welchem es um die unterschiedlichsten Formen und Normen des Lebens und Zusammenlebens geht. Adelbert von Chamissos Arbeit an der Sprache ist Arbeit am Mythos von einer Logik, einem einzigen Maßstab, der auf alle Kulturen angewendet

38 Vgl. hierzu Grober, Ulrich: Die Entdeckung der Nachhaltigkeit. Kulturgeschichte eines Begriffs. München: Verlag Antje Kunstmann 2010, S. $227 \mathrm{f}$.

39 Vgl. zu diesem Regulativ europäischer Weltaneignung Bitterli, Urs: Die „Wilden“ und die „Zivilisierten“. Grundzüge einer Geistes- und Kulturgeschichte der europäisch-überseeischen Begegnung. München: dtv 1982.

40 Chamisso, Adelbert von: Reise um die Welt, Bd. II, S. 75.

41 Vgl. zu den Formen von „Wildheit“ White, Hayden: Tropics of Discourse. Essays in Cultural Criticism. Baltimore - London: the Johns Hopkins University Press 1978, S. $80 \mathrm{f}$. 
werden könnte. Noch heute sind wir keineswegs von dieser Arbeit befreit; Chamisso aber weigert sich, einen derartigen verbindlichen Maßstab anzulegen und rücksichtslos im Weltmaßstab allen Kulturen aufzuoktroyieren.

Er konstruiert in diesem Zusammenhang keine Alterität, keinen ,Anderen“ oder ,Fremden', der sogleich inferiorisiert werden könnte, sondern versucht ein Lebenswissen zu entfalten, das sich eher in einer Epistemologie der Erweiterung ansiedelt. ${ }^{42}$ Das sich hierbei manifestierende Welterleben ist eines, das auf ein Weiter-Leben abzielt: Das sich nicht auf die engen Begriffe ,gesitteten“ oder ,zivilisierten' Lebens einlassen will, sondern eine grundlegende Weitung nicht nur imaginierbarer oder denkbarer, sondern wahrnehmbarer und deutbarer Lebensformen intendiert. In vielerlei Hinsicht ist der große romantische Dichter Deutschlands unser Zeitgenosse.

Es geht an diesem Punkte um ein Welterleben, wie es der Chamisso des Jahres 1836 immer wieder auch auf denjenigen des Jahres 1815 projiziert und so das Spiel von erzählendem und erlebendem Ich aus fast zwanzigjähriger Distanz in Gang hält. Das reiseliterarische Schreiben geht in vielen derartigen Passagen mit dem autobiographischen Schreiben Hand in Hand. In seiner Reise um die Welt plädiert der weitgereiste Preuße Adelbert von Chamisso deutlich für ein weiteres, weiter gefasstes Verstehen von (menschlichem) Leben: keines, das lediglich an der schieren Materialität des Lebensprozesses ausgerichtet ist.

Immer wieder versucht der Reisende, die verschiedenen Logiken von Europäern und indigener Bevölkerung ineinander $\mathrm{zu}$ übersetzen, indem er etwa mit erhobenen Händen fuchtelnd und schreiend auf die Menschen einer der besuchten Inselgruppen zuläuft, so dass sie die Flucht ergreifen, bevor es ihm mit Hilfe seines Lachens gelingt, die Bewohner wieder anzulocken und in eine Kommunikation mit ihnen einzutreten. ${ }^{43}$ Es sind (bisweilen naive, bisweilen raffinierte) Experimente im Zusammenlebenswissen, die immer wieder Chancen und Grenzen zwischenmenschlicher Konvivenz in einem weltweiten Maßstab erproben. Beeindruckend ist dabei die ,Gabe‘ oder vielleicht doch eher Fähigkeit Chamissos, sich auf jene Menschen einzulassen, die er nicht als ,Wilde‘, nicht als ,Fremde‘, nicht als ,Andere‘, sondern als seine Mit-Menschen zu verstehen weiß: In dieser Mitmenschlichkeit gründet seine Ethik.

So bezeichnete Chamisso im Kontext seiner Beschreibung der Insel Radack auch seinen „Freund Kadu“, der „fremd auf dieser Insel-Kette“ sich der Fahrt der

42 Vgl. hierzu Ette, Ottmar: Weiter denken. Viellogisches denken / viellogisches Denken und die Wege zu einer Epistemologie der Erweiterung. In: Romanistische Zeitschrift für Literaturgeschichte / Cahiers d'Histoire des Littératures Romanes (Heidelberg) XL, 1-4 (2016), S. 331-355. 43 Vgl. ebda., Bd. II, S. 134 f. 
„Rurik“ eine Zeitlang anschloss, als einen „der schönsten Charaktere, den ich im Leben angetroffen habe“, ja als einen „der Menschen, den ich am meisten geliebt“. ${ }^{44}$ Der Südsee-Insulaner ist als Mit-Mensch zum geliebten Freund des französischen Preußen geworden. Die Mitmenschlichkeit vermag es, bei Chamisso die Grenzen von Sprache, Kultur oder Nation zu überwinden.

Adelbert von Chamisso ist sich bei der Konstruktion seines wissbegierigen Forscher-Ichs, des weitgereisten Weltreisenden, des vielsprachigen Russen, der kein Russe, sondern Deutscher ist, eines Deutschen, der kein Deutscher, sondern Franzose ist, eines Franzosen, der kein Franzose, sondern ein Kind der Champagne war, das er längst nicht mehr sein kann, sehr treu geblieben. Kurzum: Er hielt fest an der Konstruktion eines Ich, das in seiner binneneuropäischen Zerrissenheit durch seine Weltreise für ein weiteres Welterleben geöffnet wird. Denn es sollte ihm von Beginn seiner Weltreise an ganz so „wie überhaupt in der Welt ergehen, wo nur das Leben das Leben lehrt““.45 Es ist das Motto eines Lebenswissens, das für andere Kulturen, für andere Blickwinkel, andere Lebensformen weit offen ist und ein solches Wissen vom Leben zur Grundlage des gelebten und zu lebenden Lebens macht.

Dieses Lebenswissen jedoch öffnet sich als Ergebnis eines offenen Lebensprozesses und einer Lebensgeschichte, die weit mehr ist als eine mehr oder minder geglückte Reisebeschreibung, auf eine andere Art von Wissen, die fast schon an der Schwelle zu einem weiteren Leben, ja zu einem Weiterleben steht. So lesen wir wenige Seiten vor Abschluss des „Tagebuchs“ und damit des ersten Teiles von Chamissos Reise um die Welt:

Ich meinerseits bin bei jedem neuen Kapitel meines Lebens, das ich schlecht und recht, so gut es gehen will, ablebe, bescheidentlich darauf gefaßt, dass es mir erst am Ende die Weisheit bringen werde, deren ich gleich zu Anfang bedurft hätte; und dass ich auf meinem Sterbekissen die versäumte Weisheit meines Lebens finden werde. ${ }^{46}$

Vielleicht liegt an diesem Punkt die Weisheit von Chamissos Lebenswissen: Am Ende der Reise, der Lebensreise, so die Hoffnung, könnte sich nach dem ,Ableben“ aller Kapitel das Wissen in Weisheit übersetzen, könnte das Wissen in der Weisheit aufgehen und somit weiterleben, ohne auf ein konkretes Wissen einer Wissenschaft heruntergebrochen werden zu können. Erst auf dem Sterbekissen, so

44 Ebda., Bd. II, S. 141.

45 Ebda., S. 20.

46 Ebda., Bd. II, S. 251. 
Chamissos Bild, werde jene Weisheit langsam erkennbar, die das Wissen auf ein Künftiges, ein Weiteres, auf ein Weiterleben hin perspektiviert.

Die Weisheit, so scheint der alt gewordene Dichter am Ende seines „Tagebuchs" anzudeuten, ist bestenfalls jenes Wissen, das am Ende der Reise nur vom Tod in Weisheit umgewandelt werden kann - in eine Weisheit, deren man doch viel früher, in früheren Kapiteln des Lebens so dringend bedurft hätte. Heißt dies, dass diese Weisheit, wie es der französisch-preußische Dichter anzudeuten scheint, weder transindividuell noch transgenerationell weitergeführt und damit weitergelebt werden kann? Mit anderen Worten: Was bleibt nach und von den vielen Reisen eines langen Lebens? Lässt sich ein zu Ende gegangenes Leben mit all seinem Wissen und mit all seiner Weisheit nicht weiterleben?

Das spezifische Wissen auf dem Weg zur Weisheit ist eines, das ohne den Tod und damit ohne die Transzendenz nicht auszukommen scheint. Wenn Wissen stets bei den Wissbegierigen, zu denen sich - wie wir sahen - auch der Autor zählt, letztlich nur aus der Bewegung ergibt, so wie sich die in jeglicher Hinsicht menschliche Wissenschaft nur aus der Bewegung weiter entwickeln kann, so scheint die Weisheit sich auf ein Weiterleben hin zu öffnen. Dieses siedelt sich jenseits des Raumes, jenseits der Zeit, jenseits der Bewegung an. Wir stoßen bei Chamisso auf das romantische Begehren nach einem Wissen und einer Weisheit, für welche das rationale Wissen der Aufklärung keine Messinstrumente hatte. Es ist eine Suche, welche sich nicht mit der Materialität des Wissens zufrieden gibt, sondern sich zur Transzendenz und dem Unendlichen, Unbegrenzten aufmacht.

Doch vielleicht, so könnten wir dem großen Dichter der deutschen Romantik und dem Besucher des Salons der Rahel Levin zurufen, gibt es auch hier weitere Wege des Wissens, die uns von der Wissenschaft zum Wissen und vom Wissen weiter zur Weisheit führen könnten. Denn ist es nicht statthaft, auf dem langen Weg der Suche nach wissenschaftlicher Erkenntnis auch an die Türe der Weisheit zu klopfen? Ist die Frage nach der „sapientia“ nicht eine, die sich in logischer Konsequenz aus den Bemühungen um wissenschaftliches Wissen ergibt?

Das Wissen der Wissenschaft jedenfalls kann nicht genügen! Welterleben und Weiterleben scheinen sich auch in jenem Entwurf zu begegnen, den der französische Zeichentheoretiker und Schriftsteller Roland Barthes an das Ende seiner Antrittsvorlesung am Collège de France stellte:

Es gibt ein Alter, in dem man lehrt, was man weiß; doch danach kommt ein anderes, in dem man lehrt, was man nicht weiß: Das nennt man Forschen. Es kommt jetzt vielleicht das Alter einer anderen Erfahrung: der des Verlernens, die nicht vorhersehbare Umarbeitung wirken $\mathrm{zu}$ lassen, durch die das Vergessen die Ablagerung des Wissens, der Kulturen, der Glaubensüberzeugungen, durch die man hindurchgegangen ist, prägt. Diese Erfahrung hat, glaube ich, einen berühmten und altmodischen Namen, den ich hier ohne Komplexe am 
Kreuzungspunkt seiner Etymologie aufzugreifen wage: Sapientia: keine Macht, ein wenig Wissen, ein wenig Weisheit und so viel Würze wie möglich. ${ }^{47}$

Die unermüdliche Querung unterschiedlichster Wissensformen, Kulturen und Glaubensformen führt, folgen wir Roland Barthes, zu einem Wissen, das jenseits aller Macht Weisheit als Würze, als sinnliches und sinnhaftes Welterleben versteht. Ein solches Welterleben, so die Hoffnung und die Aufgabe der Philologie, kann (und zwar nicht nur durch Editionen) weitergegeben werden. Ob es in seiner ganzen „saveur“ vielleicht auch weitergelebt werden kann, ist eine Frage, die an das Medium des Weiterlebens par excellence, an die Literaturen der Welt, aus immer neuen Perspektiven und von weiteren Kapiteln her zu stellen wäre. Dieser Suche nach dem Unendlichen und nach der Unendlichkeit des Wissens war sich der romantische Meister deutscher Verdichtungskunst sehr wohl bewusst.

Vom national noch längst nicht geeinten Deutschland ist es im 19. Jahrhundert zum ebenfalls noch nicht vereinigten Italien nur ein kleiner Sprung, den wir nun von einem preußischen Dichter französischer Herkunft zu einem der sicherlich nicht weniger großen Italienischen Dichter unternehmen: Wir kommen nun zu Giacomo Leopardi, einem der größten Vertreter der Romantik und zugleich wenn auch mit all ihren Widersprüchen - einer (exzentrischen) europäischen Moderne. ${ }^{48}$ Beschäftigen wir uns kurz mit einigen für uns wichtigen Biographemen aus Leopardis Leben!

Der italienische Poet und Philologe Giacomo Leopardi wurde in Recanati in den Marken am 29. Juni 1798 als ältestes von fünf Kindern geboren und starb in Neapel am 14. Juni 1837. Es war, wie sie sehen, ein kurzes Leben; und doch wurde Leopardi gemeinsam mit Alessandro Manzoni, mit dessen Promessi sposi wir uns leider in dieser Vorlesung nicht beschäftigen können, zu einem der ganz großen Erneuerer der Italienischen Sprache und Literatur. Er gab Impulse, die weit über Italien und Europa hinaus nicht zuletzt den hispanoamerikanischen Modernismo umfassten, ${ }^{49}$ vor allem aber die weitere Entwicklung romantischer Lyrik in Europa grundlegend prägten.

47 Barthes, Roland: Leçon. Leçon inaugurale de la Chaire de sémiologie littéraire du Collège de France, prononcée le 7 janvier 1977. Paris: Seuil 1978, S. 45 f.

48 Vgl. Neumeister, Sebastian: Leopardi und die Moderne. In: Maurer, Karl / Wehle, Winfried (Hg.): Romantik. Aufbruch zur Moderne. München: Fink 1991, S. 383-400; sowie Degner, Uta: Zentrale Randständigkeit. Zur Konstruktion von Exzentrizität in der Lyrik Leopardis und Houellebecqs. In: König, Torsten / Mayer, Christoph Oliver / Ramírez Sáinz, Laura / Wetzel, Nadine (Hg.): Rand-Betrachtungen. Beiträge zum 21. Forum Junge romanistik. Bonn: romanistischer Verlag 2006, S. 381-393.

49 Vgl. Heydenreich, Titus: Giacomo Leopardi als „Genius loci“. Über zwei Texte von José Enrique Rodó und Luis Gonzaga Urbina. In: Neue Romania (Berlin) 16 (1995), S. 27-36; sowie (ders.): 


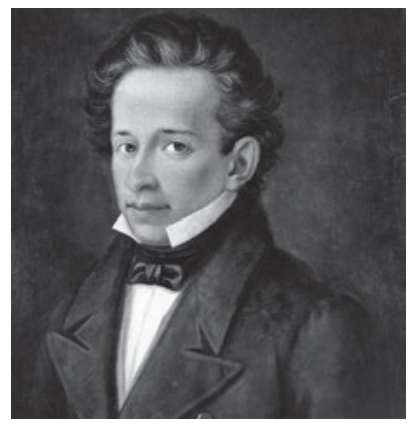

Abb. 48: Giacomo Leopardi

(Recanati, Italien, 1798 - Neapel, 1837).

Sie müssen sich Leopardi als kleinen, buckeligen und nicht eben schönen Mann von ungeheurer Gelehrsamkeit vorstellen, dem es in seinem Leben nie vergönnt war, seine Hoffnungen und Sehnsüchte jemals erfüllt zu sehen. Leopardi stammte aus einer streng katholischen, urkonservativen Adelsfamilie und wuchs in seiner damals zum Kirchenstaat gehörenden Heimatregion unter allerlei Zwängen, von gestrengen Hauslehrern erzogen auf. Früh schon bildete sich sein Interesse für die Antike heraus, wobei er hierin einer Vorliebe seines Vaters folgte und dessen Bibliothek nutzen konnte. Die ersten Arbeiten des körperlich gebrechlichen, aber geistig frühreifen Leopardi weisen ihn als einen Menschen aus, der bereits in jungen Jahren seiner Neigung zu den Wissenschaften folgte und sich im Grunde seine eigene Welt des Wissens konstruierte. In dieser Welt war Platz für erste eigene Dichtungen, für ein unbändiges autodidaktisches Sprachenlernen - er brachte sich unter anderem Griechisch und Hebräisch selbst bei -, für Übersetzungen und Editionen, so dass sich bereits während seiner Jugendzeit, in welcher noch immer die Hauslehrer das Sagen hatten, die beidseitige Leidenschaft für die Dichtung wie für die Philologie genügend Raum verschaffte: Giacomo Leopardis Welt waren die Bücher.

Bereits 1813 verfasste er eine Geschichte der Astronomie; doch zeigten sich ebenso stark seine eigenen künstlerischen Interessen. Neben seine eigene Dichtung traten bald dichtungstheoretische Überlegungen, welche Leopardi 1818 in seinem Discorso di un italiano intorno alla poesia romantica ausformulierte, eine Schrift, die freilich erst 1906 gedruckt wurde. In dieser Abhandlung eines Italieners über die Poesie der Romantik formulierte er seine Auffassung von der Notwendigkeit einer grundlegenden Erneuerung der italienischen Dichtung auf klassischantiker Grundlage. Dichtung und Dichtungstheorie der Romantik gingen bei ihm

Vollkommene Todesliebe. José Enrique Rodó (1871-1917) über Giacomo Leopardi. In: Ginestra. Periodikum der deutschen Leopardi-Gesellschaft (Bonn) (Mai 1997), S. 9-13. 
Hand in Hand; Poesie und Philologie sind die beiden Herzensschwestern seines Lebens.

Schon im Folgejahr 1819 vollzog sich, begleitet von Krankheiten, eine erste Ablösung von der Familie und der gewohnten Umgebung. Die Forschung verbindet mit dieser Phase die Entstehung von Leopardis Pessimismus, der sein gesamtes Werk kennzeichnet, der zugleich aber auch das Gegengift gegen einen blauäugigen Fortschrittsoptimismus seiner Epoche darstellt. Ab 1822 bildeten Rom, Mailand, Bologna, Florenz und Pisa die Stationen eines Lebens, das in jeglicher Hinsicht wiederholt und vergeblich nach Anschluss suchte. Zwar gelang es ihm durchaus, an einer einflussreichen Zeitschrift mitzuarbeiten und im Jahre 1826 eine grundlegend neue und von ihm kommentierte Petrarca-Ausgabe herauszubringen. Doch schaffte er es nicht, sich gänzlich von seiner konservativen Familie zu lösen und selbständig zu leben. Dem in der Forschung immer wieder auf die Freundschaft mit von Bunsen zurückgeführten Angebot, dem Ruf an die Bonner Universität auf eine Professur für Altphilologie zu folgen, leistete er, der schon früh Homer und Horaz übersetzt hatte, wohl aus gesundheitlichen Gründen nicht Folge.

Bereits 1817 hatte er mit seinen Zibaldone begonnen, seinem Sammelsurium an Notizen und Skizzen, nach denen eine heutige, vom verstorbenen Titus Heydenreich begründete romanistische Zeitschrift benannt ist. Diese philosophischliterarischen Entwürfe und Anmerkungen geben uns einen tiefen Einblick in Leopardis Werkstatt und stellen aus heutiger Sicht vielleicht sein ,modernstes‘, im Sinne Umberto Ecos ,offenstes‘ Kunstwerk ${ }^{50}$ dar.

Doch alles, was er als Philologe wie als Dichter anfasste, wurde zumindest langfristig zu einem Erfolg. Seine Liebe und seine Sehnsüchte indes blieben glücklos und unerfüllt; sie bildeten Biographeme, von denen ausgehend sich seine romantische Poesie zu entfalten verstand. Erst in den letzten Jahren seines Lebens gewann er die Unabhängigkeit von seiner Familie, von der ihn auch seine eher demokratischen Überzeugungen trennten. Seine poetischen wie literarischphilosophischen Schriften basieren auf einer Art von optimistischem Pessimismus, welcher sich für die Zeitgenossen als zeittypische Melancholie, für ein späteres Lesepublikum aber durchaus als Zeugnis einer dynamischen Energie lesen lässt.

In seiner Geschichte des Menschengeschlechts etwa sah er das Unglück der Menschen im Antagonismus von Intellekt und Phantasie verkörpert; eine Opposition, welche deutlich auf die Spannung zwischen der Aufklärung des 18. Jahr-

50 Vgl. hierzu die Umberto Eco gewidmeten Seiten im dritten „Aula“-Band von Ette, Ottmar: Von den historischen Avantgarden bis nach der Postmoderne, S. 690-704. 
hunderts ${ }^{51}$ und den starken romantischen Strömungen der Gegenwart verweist. Das Glück erblickte der Dichter auf der Seite der Phantasie. Gerade im Zusammenhang mit unseren Überlegungen zu Adelbert von Chamisso sah er die Lösung dieses Widerstreits in der Entscheidung des Menschen für eine grundlegende Mitmenschlichkeit: Auch für ihn war die Konvivenz - wenn auch aus anderen Gründen - problematisch, doch arbeitete er sich wie der Dichter der Reise um die Welt ein Leben lang daran literarisch ab.

Gerade in den Zeiten seiner psychischen Krisen und den vergeblichen Versuchen, sich aus den Fängen der Familie und der provinziellen Enge der Marken $z u$ entwinden, war ihm die Lyrik stets ein starker Trost und eine Projektionsfläche für seine eigene poetische Welt. Mit der Abfassung seiner Dichtungen hatte Leopardi - wie kurz erwähnt - bereits in seiner Jugend begonnen und legte seine berühmten Canti, die verschiedentlich, aber vor allem im Verlauf des dritten Jahrzehnts des 19. Jahrhunderts entstanden, erstmals im Jahre 1831 unter diesem Titel vor. Man kann daher ohne weiteres formulieren, dass es sich bei diesen Gesängen hinsichtlich ihres Entstehungszeitraums um sein dichterisches Lebenswerk handelt, welches zugleich den Höhepunkt der italienischen Dichtkunst der Romantik markiert. Doch auch in seinen Zibaldone wie in anderen aphoristischen Sammlungen erwies sich Leopardi als herausragender Beobachter von Menschen, der seinen Zeitgenossen skeptisch, aber stets humor- und liebevoll gegenüberstand. Für den Fortschrittsoptimismus seiner Umwelt wie für die politischen Entwicklungen in Italien hatte der Dichter freilich nur bissigen Spott übrig.

Aus dem lyrischen Gesamtwerk des mittellos und keineswegs hochverehrt verstorbenen Dichters etwas auszuwählen, ist an sich schon eine undankbare Aufgabe. Sie wird noch undankbarer dadurch, dass ich Ihnen bei Chamisso kein Beispiel aus seiner deutschsprachigen Lyrik, sondern seine brillante Prosa angeboten habe. Bei Leopardi will ich es nun zum Ausgleich umgekehrt halten und sie nicht mit seinen Zibaldone, seinen Operette morali oder seinen philosophischen Weltentwürfen, sondern mit seiner Dichtkunst konfrontieren. Ich präsentiere Ihnen in der Folge also eines der großen Gedichte Giacomo Leopardis, das unter dem Titel L'Infinito eines der vieldeutigsten Themen der Romantik, ${ }^{52}$

51 Vgl. Timpanaro, Sebastiano: Classicismo e Illuminismo in Leopardi. In: Petronio, Giuseppe (Hg.): Antologia di letture critiche. Rom - Bari 1974, S. 683-688; sowie Stierle, Karlheinz: Leopardi und die Dialektik der Aufklärung. In: Romanistische Zeitschrift für Literaturgeschichte (Heidelberg) XL, 1-4 (2016), S. 423-430.

52 Vgl. Küpper, Joachim: Giacomo Leopardis „L'Infinito“ und Friedrich Hölderlins „Die Eichbäume“. Zu einer paradoxen Konstellation in der Lyrik der europäischen Romantik. In: Comparatio. Zeitschrift für vergleichende Literaturwissenschaft (Heidelberg) I, 2 (2010), S. 207-230. 
zugleich aber auch der beiden Dichter und Denker Chamisso und Leopardi vorstellt. $^{53}$

Zentral ist in diesem Gedicht - vor dem Hintergrund unserer Überlegungen die Frage nach der Entfaltung eines von der europäischen Moderne geprägten Subjekts. Doch genießen wir zunächst das Gedicht selbst, das von keinem Geringeren als Rainer Maria Rilke ins Deutsche übertragen wurde:

\section{Die Unendlichkeit}

Immer lieb war mir dieser einsame

Hügel und das Gehölz, das fast ringsum

ausschließt vom fernen Aufruhn der Himmel

den Blick. Sitzend und schauend bild ich unendliche

Räume jenseits mir ein und mehr als

menschliches Schweigen und Ruhe vom Grunde der Ruh.

Und über ein Kleines geht mein Herz ganz ohne

Furcht damit um. Und wenn in dem Buschwerk

aufrauscht der Wind, so überkommt es mich, dass ich

dieses Lautsein vergleiche mit jener endlosen Stillheit.

Und mir fällt das Ewige ein

und daneben die alten Jahreszeiten und diese

daseiende Zeit, die lebendige, tönende. Also

sinkt der Gedanke mir weg ins Übermaß. Unter-

gehen in diesem Meer ist inniger Schiffbruch. ${ }^{54}$

\section{L'infinito}

Sempre caro mi fu quest'ermo colle, E questa siepe, che da tanta parte Dell'ultimo orizzonte il guardo esclude.

Ma sedendo e mirando, interminati Spazi di là da quella, e sovrumani

Silenzi, e profondissima quiete

Io nel pensier mi fingo; ove per poco

Il cor non si spaura. E come il vento

53 Vgl. hierzu die stark werkimmanente Studie von Wehle, Winfried: Leopardis Unendlichkeiten. Zur Pathogenese einer „poesia non poesia“. Tübingen: Narr 2000; sowie (ders.): Leopardi und die Moderne. In: Maurer, Karl / Wehle, Winfried (Hg.): Romantik. Aufbruch zur Moderne. München: Fink 1991, S. 383-400.

54 Rilke, Rainer Maria: Die Unendlichkeit. Deutsche Übersetzung von Giacomo Leopardis „L'infinito“. In: Killy, Walter (Hg.): Epochen der deutschen Lyrik. Übersetzungen. Bd. 10, Dritter Teil. München: dtv 1977, S. 703. 
Odo stormir tra queste piante, io quello
Infinito silenzio a questa voce
Vo comparando: e mi sovvien l'eterno,
E le morte stagioni, e la presente
E viva, e il suon di lei. Così tra questa
Immensità s'annega il pensier mio:
E il naufragar m'è dolce in questo mare.

Es handelt sich bei diesem Gedicht, welches das einstige Wunderkind Giacomo Leopardi im Jahre 1819 - also im Alter von einundzwanzig Jahren - verfasste und 1831 in seine Gedichtsammlung der Canti aufnahm, zweifellos um eines der berühmtesten nicht nur des italienischen 19. Jahrhunderts. Als Teil dieser zentralen Gedichtsammlung des Poeten ist es zu jenem häufig analysierten, konsekrierten und kanonisierten Kunstwerk geworden, als welches wir L'Infinito noch immer wahrnehmen.

In diesem Gedicht von sechzehn Versen, die nicht in Strophen unterteilt sind, wird schon auf den ersten Blick deutlich, dass es sich um ein verstecktes Sonett handelt, dem noch ein zusätzlicher, ein fünfzehnter Vers hinzugefügt wurde. Mit dieser Sonettform hat Rainer Maria Rilke in seiner Übertragung und Neudichtung Leopardis lustvoll gespielt. Aus dieser strukturellen Anlage können wir von Beginn an erkennen, dass es sich bei diesem fünfzehnten Vers um einen außerordentlich wichtigen Abschluss des Gedichts handeln muss.

Die zentrale Metapher dieses abschließenden Verses ist der Schiffbruch, das „naufragar“, das freilich als „dolce“, als süß besungen wird und damit keineswegs unter einem negativen Vorzeichen steht oder gar als Katastrophe markiert ist. Souverän spielt Leopardi ebenso die Form des ,klassischen' Sonetts wie auch die topische Metapher des Schiffbruchs mit Zuschauer ${ }^{56}$ gegen das Erwartbare aus. Wir hatten bereits bei Bernardin de Saint-Pierre in Paul et Virginie gesehen, dass es sich durchaus um eine Metaphorik handelt, die in der Romantik von zentraler Wichtigkeit ist und in welcher Nähe und unerreichbare Ferne zugleich zusammenlaufen. Gleichzeitig blendet diese Metaphorik eine höchst philosophische Dimension in literarische Texte über die Metapher vom Schiffbruch mit Zuschauer ein. Freilich wird in diesem abschließenden Vers das lyrische Ich zum Zuschauer seines eigenen Schiffbruchs - und zu einem glücklichen Zuschauer, der lustvoll in den Wellen versinkt. Doch so weit sind wir noch nicht! Denn zunächst können

55 Leopardi, Giacomo: L'infinito. In: Felici, Lucio (Hg.): Giacomo Leopardi. Tutte le poesie et tutte le prose. 2 Bde. Rom: Newton \& Compton 1997, S. $120 \mathrm{f}$.

56 Vgl. Blumenberg, Hans: Schiffbruch mit Zuschauer. Paradigma einer Daseinsmetapher. Frankfurt am Main: Suhrkamp 1979. 
wir festhalten, dass die Endstellung des letzten Verses und damit des gesamten Gedichts das „mare“ einnimmt, das Meer also, und damit jenes Element, in dem das lyrische Ich poetisch untergeht und sich auflöst. ${ }^{57}$

Aus dieser strukturellen Anlage ergibt sich ein doppelter Bezug zur Gesamtheit des Gedichts: Zum einen stellt sich eine Beziehung zum Titel des Gedichts, zu „L'Infinito“, dem Unendlichen her, denn das Meer steht in der Tat für jene - etwa von Gertrudis Gómez de Avellaneda oder Flora Tristan - besungene Unermesslichkeit und Unendlichkeit, in der das Ich so gerne versinkt und von der Oberfläche verschwindet. Und zum anderen entsteht eine Spannung mit dem Lexem in der Schlussstellung des ersten Verses, „colle“, dem Hügel oder Berg, der sozusagen das andere Extrem dieses Landschaftsbogens des Unendlichen ausmacht. Stets wird der Schiffbruch von einem Hügel oder Berg aus gesehen, da von einer erhöhten Beobachterposition aus der gesamte Vorgang besser überblickt werden kann. Im Gegensatz zum Meer ist der Hügel, auf welchem sich das Ich zu Beginn so wohl fühlt, deutlich umgrenzt.

Bislang haben wir uns den letzten wie den ersten Vers ein wenig näher angeschaut. Setzen wir nun zwischen dem ersten und dem letzten Vers des Gedichts die unterschiedlichen Zeitebenen miteinander in Verbindung! Wir sehen sogleich, dass der Beginn der Vergangenheit - und zwar einer lang anhaltenden Vergangenheit kraft des „Sempre“ - und der letzte Abschluss des Gedichts einer präsentisch anhaltenden Gegenwart zugeordnet werden kann, die gerade auch dadurch betont wird, dass sie an einen Doppelpunkt anknüpft und damit gleichsam eine Folgerung wie eine logische Folge des gesamten Gedichts darstellt. Denn was im letzten Vers zum Ausdruck kommt, ist in den vorherigen Versen, gleichsam im ,versteckten' Sonett, sorgsam angelegt.

Es sind Berg und Hecken und damit traditionelle Landschaftselemente - zum Beispiel - der Toskana, die zu Beginn des Gedichts eine Begrenzung des Horizonts einführen. Diese Begrenzung des Blicks wurde vom lyrischen Ich stets geschätzt. In einen Gegensatz zu den ersten drei Versen jedoch bringt sich dann nach dem „Aber“, nach dem „Ma“ eine Reflexion eines diesem alten Bild, in dem man eine Anspielung und Einspielung des alten klassischen Idylls erblicken kann, entgegenstehende zweite Partie von L'Infinito, in der nun die ,interminati spazi“ erscheinen. Diese raumbezogene Unendlichkeit, diese Ungeteiltheit wird im Gedicht im Übrigen durch ein gängiges literarisches Verfahren vorgeführt, indem die Hecke gerade nicht mehr die Versenden abtrennt, sondern durch Enjambements die Versgrenzen ständig wieder aufgehoben und verschoben werden.

57 Vgl. Herold, Milan: „Il presente non può esser poetico“, S. 128-148. 
Dabei stehen „Spazi“ und „Silenzi“ in der Versanfangsstellung, die nicht weniger betont ist, eine Anfangsstellung, in der wir im weiteren Verlauf des QuasiSonetts auch den Titel des Gedichts selbst, „Infinito“, sowie „Immensità“ wiederfinden können. Zur Räumlichkeit der Landschaft tritt ein Soundscape hinzu, eine Dimension der Stille und Ruhe, welche im weiteren Fortgang der Reflexionen des lyrischen Ich wichtig werden wird. Auf diese Weise ergibt sich bereits eine Deutungslinie, die von der kleingekammerten, von Hecken getrennten und eingeteilten Berglandschaft zur Unendlichkeit und Weite einer anderen Landschaft, die auf ein Meer hinausläuft, wie mit Hilfe einer Überblendtechnik wechselt. Das ,Spiel` mit der Idylle verrät uns, dass der italienische Dichter (und erfahrene Philologe) über den gesamten lyrischen Schatz der Antike wie der Romantik verfügt.

Die Räume und das Schweigen von übermenschlicher Qualität, die unendliche Ruhe, der sich ein gesamter Vers - „Silenzi, e profondissima quiete“ widmet, und all diese Elemente eines Gegenbildes sind freilich einer Fiktion, einem „fingere“ geschuldet, die vom „pensier“ ausgeht, also dem Denken, der Gedankenwelt, dem Rationalen des Ich. Dann aber folgt die Einführung des Herzens, jenes intimen Erkenntnisorgans, das in der Romantik stets in inneren Widerstreit mit der Vernunft, mit dem Denken in sein eigenes Recht eintritt. Dies ist eine Gegenstellung, die hier in der Mitte des Gedichts durch jene von „pensier“ und „cor“ erreicht sowie signalisiert wird. Wenn Sie die Zeilen zählen, dann sehen Sie, dass das Herz, „Il cor“, im Mittelpunkt des Gedichts, also im achten von fünfzehn Versen steht. Wir werden im weiteren Verlauf unserer Vorlesung noch oft auf das Herz des Menschen - auch in seiner Relation zum Schreiben - zurückkommen.

Nach diesem ersten Erscheinen des Herzens tritt eine signifikante Veränderung der beteiligten Sinne auf, insoweit nun weniger das Visuelle, das zu Beginn des Gedichts vorherrschte, als das Akustische in den Vordergrund gerückt wird. Zweifellos ist der visuelle Gesichtssinn eher dem Gehirn, dem Denken, dem Intellektuellen und Geistigen nahe: Nicht umsonst ist die Vision gleichsam der entfernteste Fern-Sinn, welcher die sichtbaren Gegenstände selbst über große Distanzen hinweg abtasten kann, ohne dass etwas in den Körper eindringen müsste. Der Gesichtssinn ist mithin der unkörperlichste Sinn, während das Hören deutlich dem Körper-Leib und natürlich auch dem Herzen nähersteht - schon allein aufgrund der christlichen Tradition und ihrer Besetzung der Sinne. Denn war nicht das wahre Organ des Christenmenschen nicht das Auge, welches der Verführung, der „concupiscentia oculorum“ unterliegt, sondern das Ohr, mit dem wir horchen und gehorchen, der göttlichen Stimme und der religiösen Botschaft folgen?

Hier also tritt an die Stelle des Schweigens in der Erinnerung eine Stimme, von der man behaupten kann, dass sich bereits eine Klangspur von „vento“, dem Wind über der arkadischen Landschaft, $\mathrm{zu}$ „,voce“ hinziehe und sozusagen beide 
miteinander verbinde. ${ }^{58}$ Unabhängig davon, ob man diese Klangspur nun nachvollziehen kann, tritt die Erinnerung an diese Klänge gleichsam an das geistige Ohr des lyrischen Ich, wobei die Klänge der Vergangenheit in einen Widerstreit mit der Gegenwart eintreten. Es kommt - und dies ist wichtig - zu einer Ablösung des Denkens, der Vernunft, des „pensier“, das durch seine Lexem-Rekurrenz ebenso auffällt wie die Unermesslichkeit, die „Immensità“, die sich nun des lyrischen Ich bemächtigt. Es geschieht eine Abdankung des Denkens, eine Negation der Vernunft, welche die klaren Landschaftsgrenzen durchaus noch überblickte, nun aber sich verliert und negiert, ja quasi auflöst in der Unermesslichkeit von Klängen, die nicht mehr dem Reich der Natur angehören.

Die Natur, so lässt sich zweifellos erkennen, ist nicht mehr die große trostspendende Kraft für das lyrische Ich; sie wird auch von keiner Vernunft mehr in eine solche Glücksspenderin verwandelt. Das Denken bietet keine Zufluchtsmöglichkeit mehr, sondern macht den Klängen der Erinnerung und der Sehnsucht nach der Unendlichkeit, nach dem Unendlichen Platz. Das Sich-Verlieren in diesem Meer ist nicht nur süß, sondern impliziert in diesem süßen Schiffbruch zugleich auch ein absolutes Sich-Verlieren des Ich, das zugleich mit seiner Vernunft, mit seinem Denken abgedankt hat. Das Ich spielt die Karte der Rationalität nicht mehr, denn es weiß sich nunmehr aufgehoben in einer Unendlichkeit: in einer von Chamisso sicherlich verschiedenen Unendlichkeit, welche in der Überschreitung des präzisen Denkens in das Undenkliche aber eine Übereinstimmung findet.

Das Ich steht für das moderne Subjekt, das sich zwischen Hügel und Meer zurechtfinden muss. Fühlte es sich früher noch wohl in der Natur, so kann ihm diese nun nicht länger Tröstung sein. Doch nicht allein die Natur hält keine Versprechen mehr für das moderne Subjekt bereit, sondern auch das eigene Denken, die eigene Rationalität, die dem Ich keinerlei Heilsbotschaften mehr bieten kann. So bleibt - stellvertretend für das „Infinito“ - als Drittes nur noch das Meer, das Meer einer Unermesslichkeit, in welcher sich das moderne Subjekt auf süße Weise verlieren und auflösen kann. Das Geräusch des Windes dringt an das Ohr des Ich als Ausdruck jenes Luftmeeres, das in seiner Ausdehnung ebenfalls unermesslich ist. Das Rauschen des Windes zwischen den Pflanzen ist zugleich das Geräusch, das nun gleichsam als Wind aus Arkadien die Dinge in Bewegung bringt. Denn es ist der Wind, der notwendig ist, um aufs Meer hinaus zu segeln, also jene gesicherte Hügellandschaft zu verlassen, in der sich das Ich einst wohlfühlte. Man darf in ihr eine Reminiszenz an die Heimat erblicken, wurde der Dichter doch in

58 Vgl. hierzu Wehle, Winfried: Leopardis Unendlichkeiten. Zur Pathogenese einer „poesia non poesia“. Tübingen: Narr 2000, S. 33 f. 
den Marken geboren, wo er in provinzieller Begrenztheit - für welche die Hecken stehen - groß geworden war. Das moderne Subjekt jedoch muss sich dem Unendlichen stellen!

Doch birgt das Unendliche, die Unermesslichkeit, in welcher sich das moderne Subjekt oder das Subjekt in der Moderne auf süße Weise zu verlieren droht, doch noch immer ein Glücksversprechen, ja eine Heilsbotschaft: Dieses Glück im Unermesslichen liegt in der Auflösung des Ich begründet. Denn die Offenheit und Unausmessbarkeit des Meeres bietet einen Gegen-Raum, in welchem das moderne Subjekt sich entgrenzen kann, ist die Problematik der Grenze, des Horizonts doch im Gedicht bereits ab den ersten Versen von großer Bedeutung. Der „ultimo orizzonte“ war dem Ich zu Beginn noch versperrt, nun aber steht er offen.

Die Entgrenzung des Meeres bringt freilich auch die Entgrenzung des Ich mit sich, da sich das moderne Subjekt nicht mehr im sicheren, eingefriedeten und umzäunten Bezirk auf sich selbst besinnen und diesen Raum mit seinem Denken durchdringen kann. Entgrenzung heißt Verlust von Sicherheit, Verlust der „profondissima quiete“, aber auch Gewinn des Unendlichen und Zugang zum Ewigen, zum „eterno“. In L'Infinito wird daher eine Sehnsucht nach Unendlichkeit deutlich, die - ganz im Sinne der romantischen Seele und des Traums von Albert Béguin - sich gerade als Gegenbewegung zur Aufklärung, zur Einteilung, zur Durchdringung des Verstandes profiliert, der in immer kleinere Einheiten teilt und analysiert. Dieser Bewegung eines ständigen Auseinander-Setzens stellt sich das Unermessliche, das Nicht-mehr-Ausmessbare, in seiner Unendlichkeit und Ewigkeit doch immer noch als ein Glücksversprechen entgegen. Denn das „pensier mio“ geht in der Unendlichkeit des Meeres, in einem Schiffbruch im Ewigen süß und glücklich auf.

Giacomo Leopardi weist an dieser Stelle mit seinem Gedicht von 1819 bereits unverkennbar auf eine Natur voraus, die bald nicht mehr nur abgedankt hat, sondern die zudem verspottet, verhöhnt, verhohnepiepelt wird. In dieser Phase der Romantik hält die Natur keine Versprechen mehr für den Menschen, für das Subjekt in der Moderne bereit. Sie ist nicht länger die einstmals so vertraute und die Seele des Menschen auffangende Korrespondenznatur, welche sie genauso lebendig spiegelt, wie diese umgekehrt die Natur umschlingt.

Hierin äußert sich ein Gedanke, der unruhig und beunruhigend die europäische Romantik durchläuft, in der noch immer beherrschenden Korrespondenznatur aber immer wieder die Möglichkeit einer großen Einheit von Mensch und Natur, von kosmischer Einheit offenlässt. Im einem Brief Charles Baudelaires an Desnoyers von Ende 1853 oder Anfang 1854 deutet sich dann definitiv die Verabschiedung der romantischen Natursicht an, so wie sie bei Giacomo Leopardi schon ins Wanken geraten war: 


\begin{abstract}
Mein lieber Desnoyers,
Sie bitten mich für Ihren kleinen Band um Verse, um Verse über die Natur, nicht wahr? Über die Wälder, die großen Eichen, das grüne Gras, die Insekten - die Sonne wohl auch? Aber Sie wissen doch nur zu gut, dass ich unfähig bin, mich über die Vegetabilien zu erweichen und dass meine Seele gegen jene sonderbare neue Religion rebelliert, welche stets, so will mir scheinen, für jedes spirituelle Wesen ich weiß nicht was an shocking besitzt. Ich werde niemals glauben, dass die Seele der Götter in den Pflanzen wohnt, und selbst wenn sie in ihnen wohnte, würde ich mich nur mäßig darum kümmern, und ich würde die meine von weit höherem Preise estimieren als jene der geheiligten Gemüse. Ja, ich habe sogar stets gedacht, dass es in der blühenden und verjüngten Natur etwas Unvorsichtiges und etwas Traurig-Quälendes gibt.

Da ich mich in der Unmöglichkeit sehe, Ihnen vollständig Genüge zu tun, schicke ich Ihnen, strikt den Begrifflichkeiten des Programms folgend, zwei poetische Stücke, welche in etwa die Summe der Träumereien repräsentieren, von denen ich in den Stunden der Dämmerung heimgesucht werde. In der Tiefe der Wälder, unter Gewölben eingeschlossen, welche Sakristeien und Kathedralen gleichen, denke ich an unsere erstaunlichen Städte, und die wundersame Musik, welche über die Gipfel rollt, erscheint mir wie die Übersetzung allen menschlichen Wehklagens. ${ }^{59}$
\end{abstract}

Dies ist eine der schönsten Verhohnepiepelungen romantischer Topoi der Natur, die ich kenne; ein befreiendes Lachen über die „geheiligten Gemüse“ und alle möglichen „Vegetabilien“, welche der romantische Kanon sonst noch aufzubieten hat. In dieser Briefpassage mokiert sich Charles Baudelaire auf unnachahmliche Weise über ein Naturbild, wie es der „Préromantisme“ und in der Folge die Romantik in der ersten Hälfte des 19. Jahrhunderts entwickelt hatten. Bei Baudelaire findet sich nun eine deutliche Abkehr hiervon, und es war nicht zuletzt auch diese Abkehr, die entscheidend war für viele, die Moderne gerade in der Jahrhundertmitte einsetzen und beginnen zu lassen.

Unsere Position ist eine andere, wie Sie ja bereits aus dem Eröffnungsteil unserer Vorlesung wissen. Doch scheint mir in diesen witzigen Wendungen bemerkenswert, mit welcher Direktheit und Offenheit Baudelaire eine neue ästhetische Perspektivierung unternimmt, die auf die transzendente, die religiöse Dimension frohen Herzens verzichtet und die „geheiligten Gemüse“ endgültig kompostiert. Das Transzendente wird mutig verabschiedet, es bedrängt das Ästhetische nicht mehr, das sich hier seinen eigenen Raum geschaffen hat. Der menschliche „Créateur“ ist an die Stelle des göttlichen getreten und stellt als

59 Baudelaire, Charles: Lettre à Desnoyers (1853/1854). In (ders.): Hommage à C. F. Denecourt. Fontainebleau : paysages - légendes - souvenirs - fantaisies. Texte établi par (préface de Auguste Luchet). Paris: Librairie de L. Hachette et Cie 1855, S. $73 \mathrm{f}$. 
Mensch für die Menschen seine poetischen „créations“ vor, die sich ihre Ästhetik jenseits aller religiösen Transzendenz suchen.

Vielleicht konnten wir das alles bereits bei Giacomo Leopardi in L'Infinito mit der Verabschiedung von dem von Hecken umgebenen Hügel absehen.

Keine Pflanzen, kein Gemüse, auch keine Insekten mehr; die Sonne wird verabschiedet, auch wenn sie - und dies ist nicht weniger typisch - noch immer, nun aber freilich im crepusculären Zustand bei Sonnenuntergang und im Dämmerzustand erscheint. Die Helligkeit der Aufklärung ist lange schon aus den großen Gewölben und den erstaunlichen Städten gewichen, in welchen Charles Baudelaire seine poetischen Blumen aus der Dunkelheit erzeugt.

Damit tritt gleichzeitig die Thematik des Traums und des Träumens in den Vordergrund: Nicht ganz zufällig übersendet Baudelaire Desnoyers mit diesem Schreiben zwei Gedichte, die er als Träumereien ebenfalls an der Schwelle von Tag und Nacht situiert. Entscheidend ist für den Baudelaire'schen Weg, dass sich die Autonom-Setzung des Ästhetischen gleichsam einen eigenen Raum zu suchen beginnt und wohl auch bereits gefunden hat. Mit Baudelaire beginnt, was der Freiburger Romanist Hugo Friedrich fast mit einer exorzistischen Geste in einem immer noch lesenswerten Band aus einem glücklichen Jahr als die Struktur der modernen Lyrik bezeichnete. ${ }^{60}$ Die Natur jedenfalls hat dem Dichter nichts mehr zu sagen, sie wird mitleidlos in die Vergangenheit, in die Geschichte verabschiedet, auch wenn ihr Baudelaire selbst in seinen frühen Naturbildern - und auf vermittelte Weise auch noch in seinen Fleurs du mal - ungeheure und keineswegs nur artifizielle Seiten abzugewinnen vermag.

Der im eigentlichen Sinne neue Ort dieser neuen, autonom gewordenen Ästhetik - und sicherlich bleibt diese Autonomie ganz im Geiste des französischen Feldsoziologen Pierre Bourdieu eine relative - ist die Stadt, ist das Urbane. Es sind nunmehr die „étonnantes villes“, die Stadtlandschaften also, die an die Stelle der Naturlandschaften, der Naturbeschreibungen und der Landschaftsmalerei treten: Diese Stadtlandschaften bilden die Baudelaire'schen Landschaften der Theorie. ${ }^{61}$ Sie repräsentieren das Moderne; in ihnen spiegelt sich das moderne Subjekt, das in der Natur immer weniger einen Spiegel, eine Entsprechung, eine Korrespondenz gefunden hat und finden kann. Mit Leopardi wagte sich das moderne Subjekt aufs offene Meer, in die Unendlichkeit der Ozeane - mit der Möglichkeit des Schiffbruchs.

60 Vgl. Friedrich, Hugo: Die Struktur der modernen Lyrik. Von Baudelaire bis zur Gegenwart. Hamburg: Rowohlt 1956.

61 Vgl. hierzu Ette, Ottmar: Roland Barthes. Landschaften der Theorie. Konstanz: Konstanz University Press 2013. 
Dieser neue Naturbegriff hat sich folglich bereits bei Leopardi - und damit schon sehr früh - in den verschiedenen europäischen Literaturen angedeutet, und es ist keineswegs so, dass die Verabschiedung der Natur ein Prozess gewesen wäre, der sich binnen weniger Jahre in Europa oder anderswo durchgesetzt hätte. Wie sich das Bild der Natur in einem naturräumlich ganz anderen Kontext in Amerika entfaltet, werden wir noch sehen. Denn die Verabschiedung von der Natur ist ja, wie das Baudelaire-Zitat deutlich macht, sehr ambivalent und hatte sich schon lange zuvor angedeutet. Wir werden mit Alphonse de Lamartine hierfür bald ein weiteres französisches Beispiel kennenlernen. Und letztlich zeigt sich auf der anderen Seite des Atlantik noch 1895 in den Briefen Juana Borreros eine Neubestimmung des Naturbildes, welche bei der kubanischen Lyrikerin ebenfalls zu einer Abkehr von der längst ,sanktifizierten' und damit überkommenen Natur führen sollte.

Doch es gibt noch einen weiteren Aspekt, der sich quer zu diesen Überlegungen anzudeuten scheint, ein Aspekt, der im Allgemeinen innerhalb der Naturbetrachtungen der Romantik bislang keine Rolle spielte: Er betrifft die Tatsache, dass die Entwicklung der literarischen Ästhetik in der mir bekannten Romantikforschung nur höchst selten in Zusammenhang mit der Entwicklung des Naturverständnisses in den Naturwissenschaften in Verbindung gebracht wurde. Dieser Aspekt ist jedoch von größter Wichtigkeit nicht nur mit Blick auf die europäische Romantik, sondern insbesondere auf die Romantik zwischen zwei Welten. Denn Reiseberichte europäischer Expeditionen spielten eine nicht zu unterschätzende Rolle bei der Ästhetisierung außereuropäischer Landschaften, ganz so, wie wir dies bereits in den vielfältigen Verbindungen zwischen Bernardin de Saint-Pierres Reisebericht und seinem kleinen, aber folgenschweren Roman Paul et Virginie erkennen konnten.

Darüber hinaus betrifft dieser Punkt die Tatsache, dass sich in der traditionellen Romantikforschung dieses Naturgefühl, diese Naturdarstellung selbstverständlich auf die literarische Darstellung europäischer Naturlandschaften bezieht. Dies aber, so scheint mir, ist aus heutiger Sicht nicht mehr leicht zu rechtfertigen, hat doch gerade die neuere Reiseliteraturforschung mehr als deutlich aufzeigen können, dass die von ihr behandelte Gattung, welche so lange von der klassischen Literaturwissenschaft wie von der Komparatistik vernachlässigt wurde, Impulse von größter Bedeutung gerade auch in den Bereich der Ästhetik $\mathrm{zu}$ vermitteln verstand. ${ }^{62}$ Diese Impulse wurden bis vor wenigen Jahrzehnten

62 Vgl. zur gewachsenen Bedeutung der Reiseliteraturforschung das Einführungskapitel des ersten Bandes der Reihe „Aula“, mithin Ette, Ottmar: ReiseSchreiben. Potsdamer Vorlesungen zur Reiseliteratur. Berlin - Boston: Walter de Gruyter 2020. 
wenig zur Kenntnis genommen, weil man es kaum für erforderlich erachtete, das Verständnis der deutschen oder italienischen Romantik in einem größeren europäischen Kontext zu begreifen oder gar mit den Romantiken außerhalb Europas in Verbindung zu bringen.

Dies ist einer der Gründe dafür, warum wir uns an dieser Stelle unserer Vorlesung mit einer gewissen Ausführlichkeit dem Denken und Schreiben eines Mannes zuwenden wollen, der Jahrzehnte seines Lebens - nicht immer freiwillig - in Potsdam verbracht hat: Ich meine natürlich Alexander von Humboldt, den wir bereits mehrfach erwähnt hatten, der nun aber selbst zu Wort kommen soll! Beginnen möchte ich aus gutem Grunde allerdings noch in diesem der Unendlichkeit gewidmeten Kapitel mit seinem Schreiben, wobei ich nicht chronologisch mit dem Anfang oder der Herausbildung seiner literarischen „écriture“ und seiner Art der Wissenschaft beginnen möchte, sondern Sie gleich zur späten Blüte dessen führen will, was wir in der Forschung als Humboldt'sche Wissenschaft bezeichnen.

$\mathrm{Zu}$ Beginn des zweiten, 1847 erschienenen Bandes seines Kosmos, den er im Übrigen eben hier „chez nous“ in Potsdam verfasst hat, finden wir ein langes, sehr ausführlich dokumentiertes Kapitel mit der Überschrift „Anregungsmittel zum Naturstudium“. Dieses umfangreiche Kapitel teilt sich wiederum auf in eine lange Abhandlung zur Naturbeschreibung, in eine Abhandlung über die Geschichte der physischen Weltanschauung und schließlich auch Überlegungen zur Landschaftsmalerei. Sie merken allein schon bei dieser Aufzählung, wie quälend falsch und irreführend es ist, dass die traditionelle Forschung den jüngeren der beiden Humboldt-Brüder als einen ,Naturwissenschaftler' abtat! Dies war er, aber er war dies eben zusammen mit seinen Aktivitäten als Kulturforscher, als Historiker, als Philosoph und Schriftsteller. Und während er als Naturforscher vor allem ein Objekt für die Wissenschaftsgeschichte wurde, ist er in allen anderen Bereichen auch mehr als zweihundertfünfzig Jahre nach seiner Geburt im epistemologischen Zusammendenken unterschiedlichster Disziplinen von größter Aktualität.

Ich möchte mich an dieser Stelle nur auf Humboldts Überlegungen zur historischen Entfaltung der Naturbeschreibung beziehen: In diesem umfangreichen Kapitel sehen wir, wie die Darstellung der Natur seit der abendländischen Antike verfolgt wird. Sehr aufmerksam werden dabei die Griechen und die Römer, aber auch das antike Christentum auf die Frage durchgesehen und analysiert, in welcher Form die Natur dargestellt, eine Naturbeschreibung vorgenommen und entfaltet wird. Alexander von Humboldt hat sich im Unterschied zu anderen Darstellungen damit aber nicht begnügt, denn er bezog in seine Überlegungen ebenfalls Indien und die Perser mit ein. Er äußerte sich vor allem auch zu den Hebräern, was in einem Aufsatz von Honigmann zu Recht sehr positiv vermerkt 
und in einen wohltuenden Kontrast zu der im Deutschland des 19. Jahrhunderts üblichen Abwertung jüdischer Kultur gestellt wurde. ${ }^{63}$

Erst danach widmete er sich der historischen Entwicklung von Naturbeschreibungen bei europäischen Schriftstellern seit der Renaissance. Ich sage mit Bedacht: bei europäischen Schriftstellern, denn gerade die Darstellung außereuropäischer Landschaften spielte bei ihm eine außergewöhnliche Rolle. Auf diese Weise bewegen wir uns mit Alexander von Humboldt durch die Zeit auf einer Zeitreise, welche zugleich einen enormen geographischen und kulturellen Raum abschreitet: Genau hierin liegt sicherlich eines der bedeutungsvollsten Verdienste des großen preußischen Schriftstellers.

All dies macht Alexander von Humboldt für uns heutzutage - im Grunde erst wieder - zu einem anregenden Zeitgenossen. Zugleich zeigt sich, wie weit er in seiner Darstellung der Natur im Jahre 1847, also wenige Jahre vor Baudelaires Brief an Desnoyers, entfernt ist von zeitgenössischen Entwicklungen im Bereich der Ästhetik. Zweifellos liegt dies zum einen an der Autonomisierung der Literatur, insbesondere aber auch der Kunstreflexion und Ästhetik gegen Mitte des 19. Jahrhunderts, so dass sich eine gegenüber der naturwissenschaftlichen Natur gänzlich andere Kunst-Natur herauszubilden beginnt. Sicherlich verkörperten Leopardi und Baudelaire in der ersten Hälfte des Jahrhunderts in der Ästhetik sehr avancierte Standpunkte; und der Autor des Kosmos wäre ästhetisch einem Adelbert von Chamisso wesentlich näher gewesen. Humboldts eigene ästhetische Position, die natürlich in bestimmten Parametern der Aufklärung verbunden ist, vor allem aber den Schwerpunkt auf ein Zusammendenken von Analyse und Synthese sowie die Erfassung eines Naturganzen legte, ist zweifellos von der Entwicklung zur Romantik, insbesondere auch durch den französischen Préromantisme geprägt. Dies sollte uns nicht verwundern, kann man den etwas mehr auf Französisch als auf Deutsch publizierenden Autor doch als einen veritablen französischen Schriftsteller ansehen. ${ }^{64}$

63 Vgl. hierzu - wir waren ja bereits auf die Freundschaft Alexanders mit Rahel Levin Varnhagen gestoßen - die Arbeiten von Honigmann, Peter: Über den Unterschied zwischen Alexander und Wilhelm von Humboldt in ihrem Verhältnis zu Juden und Judentum. In: Heuer, Renate / Wuthenow, Ralph-Rainer (Hg.): Konfrontation und Koexistenz. Zur Geschichte des deutschen Judentums. Frankfurt am Main - New York: Campus Verlag 1996, S. 46-81; ders.: Alexander von Humboldts Verhältnis zu Juden. In: Bulletin des Leo Baeck Instituts 76 (1987), S. 3-34; ders.: Der Einfluß von Moses Mendelssohn auf die Erziehung der Brüder Humboldt. In: Mendelssohn-Studien 7 (1990), S. 39-76; sowie ders.: Judaica in der Bibliothek Alexander von Humboldts. In: Marginalien - Zeitschrift für Buchkunst und Bibliophilie LXXXVI, 2 (1982), S. 16-36.

64 Vgl. hierzu Lenz, Markus Alexander: Französische Literaten. In: Ette, Ottmar (Hg.): Alexander von Humboldt Handbuch. Leben - Werk - Wirkung. Mit 52 Abbildungen. Stuttgart: J.B. Metzler Verlag - Springer Nature 2018, S. 229-235. 
Doch ließe sich zugleich die Ansicht vertreten, dass Humboldt die weiteren Entwicklungsschübe innerhalb der europäischen Romantik nicht mehr mitging. Eine derartige ästhetische Positionierung wird nach meinem Dafürhalten deutlich in jenen Darstellungen des Siebenundsiebzigjährigen, die ich Ihnen gerne in einem nicht allzu langen Auszug aus dem zweiten Band seines Kosmos vorstellen möchte: Humboldt äußert sich zunächst zu Graf Buffon, bringt dort aber manche Kritik an, die auch mit seiner Kritik an einer eurozentrischen Aufklärung in engster Verbindung steht. Danach gelangt er zum letzten historischen Abschnitt seiner Betrachtung der von ihm untersuchten Naturdarstellungen. Ich versuche, Ihnen eine lange Passage gut gegliedert zu kürzen:

Größere Tiefe der Gefühle und ein frischerer Lebensgeist atmen in Jean Jacques Rousseau, in Bernardin de St. Pierre und in Chateaubriand. Wenn ich hier der hinreißenden Beredsamkeit des ersten [...] erwähne, so ist es, weil in den Hauptwerken des wenig gelehrten, aber eifrigen Pflanzensammlers [...] die Begeisterung sich hauptsächlich in der innersten Eigentümlichkeit der Sprache offenbart, ja in der Prosa ebenso überströmend ausbricht als in Klopstocks, Schillers, Goethes und Byrons unsterblichen Dichtungen. [...] Indem wir zu den Prosaikern wieder zurückkehren, verweilen wir gern bei der kleinen Schöpfung, welcher Bernardin de St. Pierre den schöneren Teil seines literarischen Ruhmes verdankt. „Paul und Virginia“, ein Werk, wie es kaum eine andere Literatur aufzuweisen hat, ist das einfache Naturbild einer Insel mitten im tropischen Meere [...]. Viele Jahre lang ist es von mir und meinem treuen Begleiter und Freunde Bonpland gelesen worden; dort nun (man verzeihe den Anruf an das eigene Gefühl) in dem stillen Glanze des südlichen Himmels, oder wenn in der Regenzeit, am Ufer des Orinoko, der Blitz krachend den Wald erleuchtete, wurden wir beide von der bewunderungswürdigen Wahrheit durchdrungen, mit der in jener kleinen Schrift die mächtige Tropennatur in ihrer ganzen Eigentümlichkeit dargestellt ist. Ein solches Auffassen des Einzelnen, ohne dem Eindruck des Allgemeinen zu schaden, ohne dem zu behandelnden äußeren Stoffe die freie innere Belebung dichterischer Phantasie zu rauben, charakterisiert in einem noch höheren Grade den geistreichen und gefühlvollen Verfasser von Attala, René, der Märtyrer und der Reise nach Griechenland und Palästina. In seinen Schöpfungen sind alle Contraste der Landschaft in den verschiedenartigsten Erdstrichen mit wundervoller Anschaulichkeit zusammengedrängt. Die ernste Größe historischer Erinnerungen konnte allein den Eindrücken einer schnellen Reise Tiefe und Ruhe verleihen. [...]

Was die neuere Kultur uns gebracht, ist die unausgesetzt fortschreitende Erweiterung unseres Gesichtskreises, die wachsende Fülle von Ideen und Gefühlen, die tätige Wechselwirkung beider. [...] Durch Georg Forster begann eine neue Ära wissenschaftlicher Reisen, deren Zweck vergleichende Völker- und Länderkunde ist. [...] Alles, was der Ansicht einer exotischen Naturwahrheit Individualität und Anschaulichkeit gewähren kann, findet sich in seinen Werken vereint. [...] Naturbeschreibungen können scharf begrenzt und wissenschaftlich genau sein, ohne dass ihnen darum der belebende Hauch der Einbildungskraft entzogen bleibt. Das Dichterische muß aus dem geahnten Zusammenhang des Sinnlichen mit dem Intellektuellen, aus dem Gefühl der Allverbreitung, der gegenseitigen Begrenzung und der Einheit des Naturlebens hervorgehen. Je erhabener die Gegenstände sind, desto sorgfältiger muß der äußere Schmuck der Rede ver- 
mieden werden. Die eigentliche Wirkung eines Naturgemäldes ist in seiner Komposition begründet [...]. ${ }^{65}$

In diesen Überlegungen Alexander von Humboldts drückt sich auf eine gewisse Weise das romantische Begehren und der Versuch aus, die verschiedenen Aspekte und Perspektiven des Naturgemäldes zusammenzuhalten und damit die unendliche Vielzahl unterschiedlichster Wissensbestände in ein einziges Bild der Natur nicht allein wissenschaftlich, sondern auch ästhetisch zu integrieren. Das Ästhetische - und damit ebenso die Literatur wie etwa die Landschaftsmalerei - war bei diesem Versuch nicht bloßer Zierrat, nicht bloßer Schmuck, sondern das eigentliche Verbindungswissen: jenes Wissen also, das es ermöglichen konnte, alle Wissensbestände gemeinsam und gleichzeitig miteinander in Beziehung zu setzen.

Zwar baut Humboldt genau auf jene nachaufklärerische Synthese, auf jenes Zusammenhalten der unterschiedlichen Aspekte, welches ebenso die Präromantik wie auch die deutsche Klassik im Pendelschlag gegen die analytisch-rationale Aufklärung eingefordert hatten; zwar betont auch er die in der Romantik so beliebten Kontraste, die sich zwischen den einzelnen Szenerien seiner Landschaften herstellen sollen; zwar hebt auch er eine wechselseitige Beziehung von Ideen und Gefühlen, von Sinnlichem und Intellektuellem hervor, wie es programmatisch etwa von Schelling eingefordert worden war; zwar akzentuiert er auch die Dimension einer weltweit zu untersuchenden und ästhetisch darzustellenden Natur: Doch insgesamt wirkt diese Passage wie die Auflistung des Gewesenen, welches nun in ein Neues überführt werden muss. Es wäre deshalb irreführend, Humboldt als einen Romantiker zu bezeichnen. Nichts aus der langen Geschichte der Naturdarstellungen geht in diesem seinem Gemälde verloren, es versammelt eine Unendlichkeit von Perspektiven, aber alles entwickelt sich hin zu einem qualitativen Sprung, zu etwas Neuem, welches das 19. Jahrhundert noch nicht heraufführen konnte: ein neues, epistemologisch weiteres Zusammendenken von Natur und Kultur, das erst in unserer Zeit wieder möglich scheint.

Wir haben es folglich nicht mit einem Abgesang auf eine verlorene Zeit zu tun: Humboldt war sich zum damaligen Zeitpunkt durchaus bewusst, dass die Grundlagen seines Denkens im besten nietzscheanischen sinne unzeitgemäß waren. Doch er versteht es klug, seine vorauseilenden Gedanken auf die vorherrschenden Entwicklungslinien seiner Epoche zurückzuführen, welche seiner ,Summa‘, seinem Kosmos auch den ungeheuren internationalen Bucherfolg bescherten,

65 Humboldt, Alexander von: Kosmos. Entwurf einer physischen Weltbeschreibung. Bd. 2. Stuttgart - Tübingen: Cotta 1847, S. 66-74. 
der bereits dem ersten Band zuteil geworden war. Denn die ganze lange Passage endet mit einer Eloge auf den großen Dichter des deutschen Vaterlandes, um den uns die gesamte Welt beneide, auf Johann Wolfgang von Goethe also, in dem das Naturgefühl stets die dichterische Sprache durchdrungen habe.

Damit aber wird die durchaus ambivalente, ja vieldeutige Haltung Alexander von Humboldts zwischen französischer Aufklärung, deutscher Klassik, zwischen französischer Frühromantik und deutscher Romantik deutlich, welche er selbst $\mathrm{zu}$ einem außerordentlichen Werk des Zusammendenkens und der Vernetzung des Naturwissenschaftlichen mit dem Kulturwissenschaftlichen, des Intellektuellen mit dem Sinnlichen weiterzuentwickeln vermochte. Der Schlüssel für diese Einbeziehung des im Grunde Unendlichen war zum einen das transdisziplinäre Moment, das all seinem Denken innewohnt und alle verschiedenen Wissensbereiche zusammenzuführen versucht, sowie das transareale, in welchem sich eine keineswegs nur auf Preußen oder Europa begrenzte Vorstellungswelt ausdrückt.

Nicht zuletzt ist es die weltweite, die kosmopolitische Dimension seines Denkens und seiner Vorstellungen, die $\mathrm{zu}$ jenem Zeitpunkt längst minoritär geworden war und jenen neuen Konzeptionen des Nationalen und der Nationalstaaten Platz gemacht hatte. Einem solchen Denken in Homogenitäten hatte ein Johann Gottlieb Fichte in Deutschland den Weg bereitet; und ihm stand auch ein Wilhelm von Humboldt in seinen Kommentaren etwa zur Behandlung der Judenfrage nahe, insofern er einen liberal gedachten Weg wies, auf dem die kulturelle Andersheit der Juden möglichst rasch beseitigt und getilgt werden sollte. Dass Wilhelm von Humboldt dabei gerade die „billige Toleranz“ als das geeignetste Mittel erschien, um eine Homogenität des zu schaffenden Staatsgebildes zu erzielen, kann an dieser Stelle nur gestreift werden: Gerade beim Denken der Toleranz gab es zwischen beiden Brüdern deutliche Unterschiede. ${ }^{66}$

Alexander von Humboldts Naturgemälde aber, in welchem sich die Synthese einer komplexen Übergangsepoche ausdrückt, war für die weitere Entwicklung der Romantik nicht mehr maßgeblich. Die Ausdifferenzierung des Ästhetischen war weiter fortgeschritten. Und die Radikalisierung des Individualitätsbegriffs riss das moderne Subjekt zunehmend in den Strudel eines Gegensatzes zur Natur und Naturbetrachtung, in welchem wie schon bei Giacomo Leopardi eine Darstellung der Natur als eingehegte Idylle zwar noch aufscheinen mochte, aber ästhetisch nicht länger durchführbar war. Die einzelnen überkommenen Ele-

66 Vgl. zum Toleranzbegriff das Schlusskapitel „Differenz Macht Toleranz. Acht Thesen“ in Ette, Ottmar: ÜberLebenswissen. Die Aufgabe der Philologie. Berlin: Kulturverlag Kadmos 2004, S. 253-277. 
mente der Naturdarstellungen in der Romantik wurden - wie in Madame Bovary von Gustave Flaubert - zwar zitierbar, freilich nur noch, um im selben Atemzug endgültig verabschiedet zu werden. Mit dem unzeitgemäßen Alexander von Humboldt allerdings verbindet sich eine Position, an welche erst seit Ende der zweiten Hälfte des 20. Jahrhunderts wieder produktiv angeknüpft werden konnte. 